Review Article

Martha V. Velasco, Marina T. Souza, Murilo C. Crovace*, Adilson J. Aparecido de Oliveira, and Edgar D. Zanotto

\title{
Bioactive magnetic glass-ceramics for cancer treatment
}

https://doi.org/10.1515/bglass-2019-0013

Received Sep 25, 2019; revised Nov 17, 2019; accepted Nov 24, 2019

Abstract: After five decades of research on bioactive glasses and glass-ceramics, these materials became of considerable interest due to their revolutionary potential for numerous health applications, including cancer treatment. One advantage of glass-ceramics compared with other materials - such as metallic alloys and polymers - is their capability of being highly bioactive and, if desired, containing magnetic phases. Hyperthermia (HT) is an alternative for treating cancer; the strategy is to increase the temperature of the tumor using an external magnetic field that increases the temperature of an implanted magnetic material, which works as an internal heat source. This local increase of temperature, ideally to $\sim 43^{\circ} \mathrm{C}$, could kill cancer cells in situ without damaging the healthy surrounding tissue. To achieve such goal, a material that presents a balance between proper magnetic properties and bioactivity is necessary for the safe applicability and successful performance of the HT treatment. Certainly, achieving this ideal balance is the main challenge. In this article we review the state-of-the-art on glass-ceramics intended for HT, and explore the current difficulties in their use for cancer treatment, starting with basic concepts and moving onto recent developments and challenges.

Keywords: Glass-ceramic; bioactive; magnetic; hyperthermia, cancer

\footnotetext{
${ }^{\star}$ Corresponding Author: Murilo C. Crovace: CeRTEV - Center
for Research, Technology and Education in Vitreous Materials

*Corresponding Author: Murilo C. Crovace: CeRTEV - Center
for Research, Technology and Education in Vitreous Materials (LaMaV/DEMa), Federal University of São Carlos (UFSCar), São Carlos - SP, Brazil; Email: murilocc@yahoo.com.br Martha V. Velasco, Marina T. Souza, Adilson J. Aparecido de Oliveira, Edgar D. Zanotto: CeRTEV - Center for Research, Technology and Education in Vitreous Materials (LaMaV/DEMa), Federal University of São Carlos (UFSCar), São Carlos - SP, Brazil
}

\section{Introduction and historical background}

Cancer is one of the most challenging and not satisfactorily solved problems of modern medicine. For this reason, it is one of the most deadly and investigated diseases. This disease typically occurs with the development of a malignant tumor that derives from a "renegade" cell [1, 2]. This type of cell has damaged DNA that cannot (normally) be repaired by their own mechanisms. Cells have evolved a network of DNA repair mechanisms to remove different types of DNA damage. Regardless of the nature of the lesion and the mechanism required for their repair, cells initiate a highly coordinated cascade of events, known as the DNA damage response (DDR), which senses the DNA damage, signals its presence, and mediates repair [3]. When this mechanism fails, the damaged cells grow without control, and the DDR cannot arrest the cell cycle to allow for efficient DNA damage repair before replication or mitosis or signal cells, leading to the development of a malignant tumor. Normal healthy cells grow, divide and die in a definite way, while cancer cells grow uncontrollably. Cancerous growth has six essential alterations: self-sufficiency in growth signals, insensitivity to growth-inhibitory (antigrowth) signals, evasion of programmed cell death (apoptosis), limitless replicative potential, sustained angiogenesis, and tissue invasion and metastasis [4]. They are not sensitive to growth inhibitors, avoiding apoptosis and have unlimited replicating potential in addition to enhanced angiogenic and dissemination (invasive) potential [5].

Nowadays, the cure for cancer heavily relies on the stage it is detected; for most cancer types, complete cure is not yet a reality. The current challenge is the development of a therapy that heals this potentially fatal disease, with minimum side effects. Today, three main therapies are being used in clinical practice: surgery, radiotherapy, and chemotherapy - which includes many novel types of therapies [1]. Most of these therapies provide solutions that are not selective enough because they destroy not only the cancer cells, but also the healthy cells. 
For a less invasive treatment, it is essential to consider that the destruction of cells does not expand into a dangerously large part of the body or paralyzes vital body functions [6]. Disturbance of the standard features of healthy organs is one of the main disadvantages of (most) of the current oncology treatments [1]. The efficiency of chemotherapeutic, as well a radiotherapeutic cancer treatment is generally restricted by the expression of multidrug resistance (MDR) transporters that confer resistance to a variety of structurally unrelated, clinically important antineoplastic agents $[5,6]$. For a cancer therapy to be successful there should be a balance between the toxic tolerance and the desirable destruction of cancer cells. The high toxicity of most drugs used, and the imbalance between available therapeutic options and their strong side effects have lead to research on alternatives methods, such as hyperthermia [1].

Hyperthermia (HT) is a method of killing cancer cells in situ, through the local application of heat. HT comprises completion of physical processes, using non-ionizing radiation or convective/conductive mechanisms, to heat a specific area of interest [9]. This method is idealized to treat tumors by increasing their temperature using an implanted magnetic material that is activated by an external magnetic source. By locally increasing the tissue temperature, cancer cells can be killed or impeded to grow; therefore, this technique uses no chemical substances or presents severe toxicity [10]. It is a clean alternative to treatments based on microspheres containing radionuclides, because of the absence of ionizing radiation.

There are three main types of hyperthermia treatment: whole body, regional and localized hyperthermia.

Whole body hyperthermia (WBH) uses either radiation heat or extracorporeal technologies to raise the temperature of the entire body to at least $41^{\circ} \mathrm{C}$. The typical method used for WBH is immersion in hot water bath and radiant heat by ultraviolet. In radiant $\mathrm{WBH}$, heat is superficially applied to the whole body using warm blankets, inductive loops, or thermal chambers [11, 12].

Regional hyperthermia: In the regional perfusion HT procedure, part of the patient's blood is removed, heated, and then pumped back into the limb or organ, normally along with anticancer drugs. It is usually used to treat advanced tumors located in the pelvis, abdomen, or thighs. However, regional HT is complex mainly due to differences in the physical and physiological properties of different tissues [10].

Local hyperthermia: Local HT is devoted to relatively small tumors (up to 5-6 cm), located superficially or within an available body cavity such as the rectum or esophagus. In local HT, superficial, intraluminal appli- cators are used and, most frequently, microwaves, radio waves, or ultrasound can be applied to convey heat directly to the tumor [11].

The use of HT to treat diseases is as old as medicine itself [10]. HT has been applied since the time of the ancient Greeks, 5,000 thousand years ago. Since then, methods used for hyperthermia were cauterization of surface tumors by application of a hot iron, whole-body immersion in a hot water bath, intentional inoculation of pyrogens [13]. In the modern medicine era, the pioneer in the concept of hyperthermia was Georges Lakhovsky, a physicist at the University of Paris [14]. During the First World War, Lakhovsky joined the French army and devised an improved method of laying railroad tracks. After the WWI, he was interested in wireless transmission and in the biologic application of radio waves. He was the first person to design and build the so-called a "Shortwave Diathermy" machine [14]. His early experiments with this machine, carried out in 1923, aimed for the induction of artificial fever, for the treatment of patients with malignant tumors [15]. The first patient treated at the Hospital of the Salpêtrière in 1924. The frequencies used by Lakhovsky were $0.75 \mathrm{MHz}$ to $3000 \mathrm{MHz}$, parameters that are still within the range that is used today in clinical HT [9, 10]. In 1931, he began using a machine that emits radio waves of multiple different wavelengths [14].

The potential use of local heating by hysteresis of ferromagnetic particles was first reported by Gilchrist in 1957 [16], when he was attempting to destroy metastatic cancer from the gastrointestinal tract. A comparison was made, using extensive animal studies, between hysteresis hyperthermia and eddy current hyperthermia produced by microwave generators [17].

There are different types of HT therapies, classified according to the nature of the heating source. The main heating sources fall in three categories [13]: contact with externally heated liquid, contactless application (e.g., ultrasound, microwave, radiofrequency and infrared devices), and inserted heating source (e.g.. probes, antennas, laser fibers and the so-called "mediators"). Radiofrequency, microwave, and laser-based hyperthermia allow for less invasive treatments but still require the insertion of a probe into the lesion to be treated [18]. Among the most recent hyperthermia devices, those that are based on focused ultrasound or electromagnetic radiation are commercially available. Nevertheless, none of these devices can accurately deliver high thermal energy to deeply situated cancers without destroying the surrounding healthy tissues, leading to the parallel development of technologies based on inserted heating sources [13]. 
Unlike other inserted heating sources, e.g., optical fibers, radiofrequency and microwave antennas, mediators convert the electromagnetic energy into heat when exposed to an external electrical or magnetic field. Macroscopic mediators are inserted within the body by surgical intervention, whereas micro- or nano-scale mediators injected intravenously. Interstitial macroscopic mediators for magnetic hyperthermia are generally ferromagnetic rods or seeds directly inserted into tumor tissues. These thermoseeds are typical of the order of $1 \mathrm{~mm}$ in diameter and 1-7 cm in length. These mediators can reach the tumor site by using four distinct strategies: arterial embolization hyperthermia (AEHT - through the arterial supply of the tumor, to enable embolization of the tumor), direct injection hyperthermia (DIHT - directly injected into the tumor), intracellular hyperthermia (IHT - when the particles are injected intravenously or directly into the tumor and penetrate the cancer cells) and interstitial implant hyperthermia (IIHT - when coarse articles or small rods implanted into the tumor). The pros and cons of each of these techniques have been reviewed by Moroz et al. [19]. Their use appears as the most promising cancer hyperthermia therapy, in particular, because of the better temperature homogeneity [20]. Before the heat treatment, their exact location may be determined by magnetic resonance imaging, taking advantage of their magnetic properties.

HT influences tumor blood flow, reducing oxygen/nutrient supply as well as the cellular immune response [21]. The thermal dose required to change the blood flow inside a tumor varies between individual tumors and tumor types. Figure 1 presents a scheme of how the HT technique kills tumor cells. Proteins appear to be the first target of hyperthermia in the clinically-relevant temperature range of 39 to $45^{\circ} \mathrm{C}$ (Figure), this temperatures can increase the rates of biochemical reactions, and this would increase cell metabolism, which should cause increased oxidative stress. Levels of reactive oxygen species (ROS) were shown to increase after exposure to both lethal $(\geq$ $\left.42^{\circ} \mathrm{C}\right)$ and non-lethal $\left(40^{\circ} \mathrm{C}\right)$ temperatures, would arise principally from the increased generation of ROS such as superoxide and hydrogen peroxide $\left(\mathrm{H}_{2} \mathrm{O}_{2}\right)$, likely as a result of the dysfunction of the mitochondrial respiratory chain [22]. The microenvironment of malignant tumors characterized by a lower blood vessel density and, therefore, a reduced blood flow, which favors hypoxia and acidosis [21]. The acidic environment of tumor confers resistance to radiation, but favors cell death due to heat [10]. Tumor hypoxia may present a severe problem for radiation therapy (X and Y-radiation) because radio sensitivity is progressively limited when the $\mathrm{O}_{2}$ partial pressure in a tumor is less than $25-30 \mathrm{mmHg}$ [23]. While oxygen concen- tration does not influence the response of cells exposed to hyperthermia at the time of treatment, previous studies have shown that maintenance of cells under hypoxia before to heat treatment may increase cell death [24].

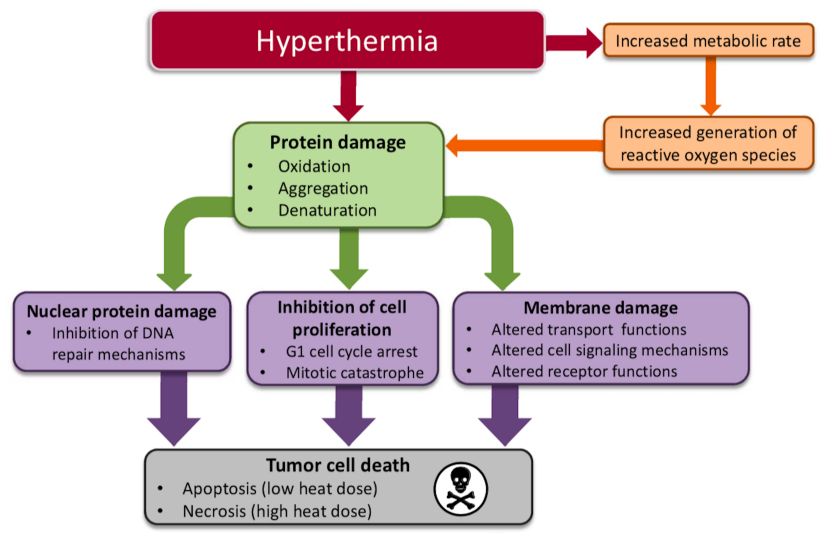

Figure 1: Basic scheme of how HT treatment leads to tumor cells death [22].

HT has a synergistic effect when combined with other cancer therapies. The application of heat has been shown to modify both the radio sensitivity and chemo sensitivity of cells [25], increasing the efficiency of these therapies. This synergistic effect results in an increase of cancer cell killing even at lower temperatures, which is not the case when HT therapy is practiced alone. The substantial reason to believe that HT therapy is promissory comes from impressive positive results in several phase- 3 clinical trials on patients with advanced malignant tumors. Improved outcome and higher survival rates were observed in patients treated using HT combined with radiotherapy when compared to radiotherapy alone [21]. Success of cancer treatment by HT is achieved when all cancer cells are ultimately killed. It means that these cells will no longer have the ability to reproduce.

Several studies showed the application of these magnetic nanoparticles for tissue engineering and regenerative medicine, indicating that such stimulations could be also helpful for tissue regeneration. In these structures, the magnetic particles attach to the cell membrane and upon the use of a magnetic field, activate the membrane and initiate some biochemical reactions within the cell, not only upholding the growth of functional bone and cartilage but also enhance tissue regeneration. Recently a revival of attention in the field of hard magnetic particles. Specially used in glass-ceramic matrix. The progress of magnetic bioactive glass-ceramics has received much attention as a thermo-seed in hyperthermia treatment of 
cancer, particularly deep-seated bone tumors, although there are still major drawbacks to overcome, the proponents of this approach are optimistic, indicating that magnetic bioactive glass-ceramics and mesoporous bioactive glasses would be effective to treat cancerous cells [26, 27].

Ideally, the applied heat should damage not only tumor cells, but also the tumor vascular system. Based on several studies regarding the hyperthermia of healthy tissues and tumors (animal and human cells), Dickson et al. [28] concluded that the ideal temperature for cancer treatment would be around $42^{\circ} \mathrm{C}$. Above $42^{\circ} \mathrm{C}$, inhibition of metabolism is more rapid in the tumor cells, but healthy tissues also become progressively affected. At temperatures below $42^{\circ} \mathrm{C}$, but above body temperature, HT has been proven to improve tumor blood flow [21]. Moreover, there is evidence that an accelerated metabolism and dissemination of tumor occurs.

To further understand the temperature dependence of cell killing, many authors have analyzed Arrhenius plots [25] when the survival curves for several temperatures were known. In the range $42-43^{\circ} \mathrm{C}$, a break (change in the slope) is observed. From these Arrhenius plots, an activation energy for the reaction that leads to cell death can be established. Activation energies of about $140 \mathrm{Kcal} / \mathrm{mol}$ were obtained in the temperature range $43-47^{\circ} \mathrm{C}$ by Henle et al. in 1983 [29]. This value is closely correlated to that needed for cellular protein denaturation in vitro [21]. This strong similarity leads to the hypothesis that the cytotoxic effect of hyperthermia is mainly denaturation of cytoplasmatic and membrane proteins. It was observed in vitro (as well as in vivo) that for temperatures below the break of the Arrhenius plot, the activation energy is considerably higher [21]; possibly indicating the existence of different mechanisms of cell death below and above the breakpoint [25].

Figure 2 shows results for hyperthermia of normal tissues studied in vivo over the same temperature range as that for tumors. Above $44^{\circ} \mathrm{C}$, the time/temperature relationship for the normal tissues (human and pig skin, rat testis, and liver) is similar to that for tumors, with the respective lines intersecting at about $46^{\circ} \mathrm{C}$. Below $44^{\circ} \mathrm{C}$, the time base for normal tissues is increased compared to that for tumors, so that a change of $1^{\circ} \mathrm{C}$ is equivalent to altering the heating time by a factor of more than 2. It is necessary to clarify that the times given in Figure 2 refer to conditions that are not normalized for the numerous tumor types. The tumors were of different volume in various anatomical sites and heated by different methods. Here only the temperature is considered; no account is taken of the possible role of the immune response or other factors of the host reaction to tissue damage.

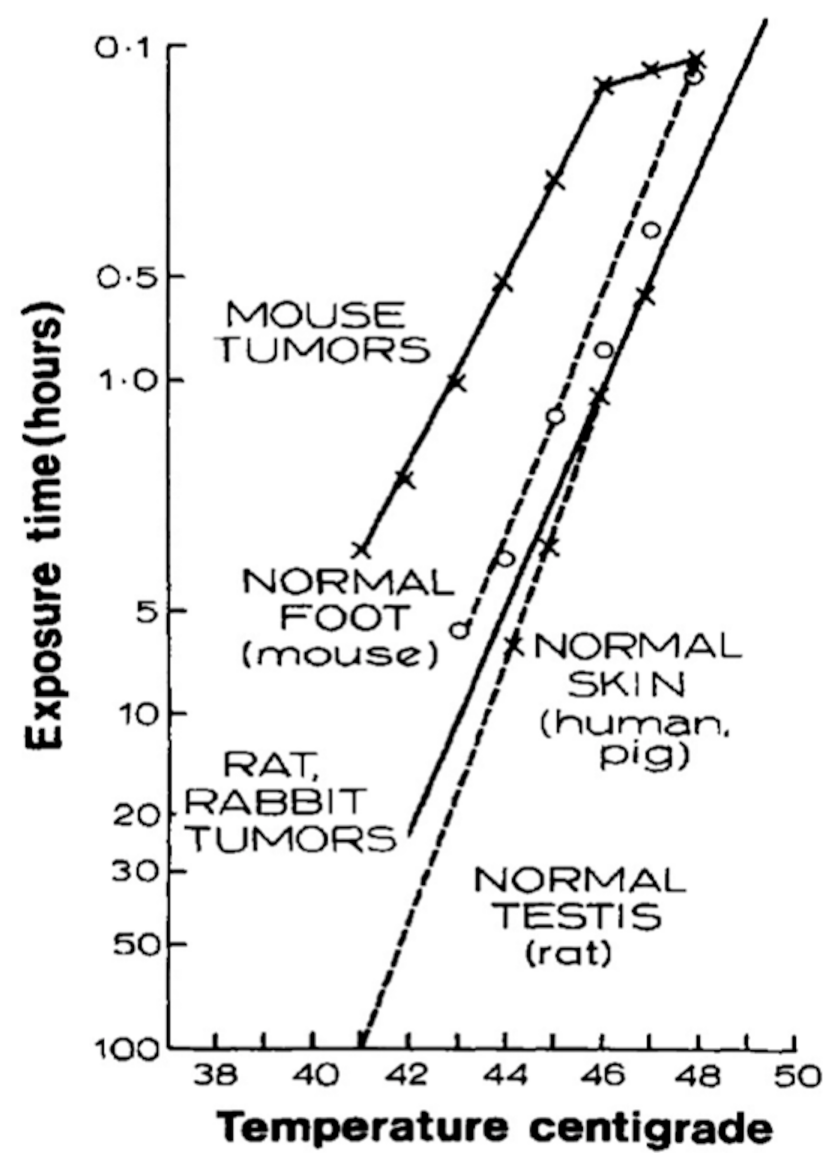

Figure 2: Time necessary to kill animal and human tumors (in vivo) as a function of temperature. The data is compared with the required time to kill normal tissues. Data for normal human and pig skin begin at $44^{\circ} \mathrm{C}$ and extend to higher temperatures, as do Westermark's values for rat testis germinal epithelium and liver. The data of Fukui for germinal epithelium of testis extend from 41 to $48^{\circ} \mathrm{C}$. Figure extracted from [28].

\section{Magnetic-induced hyperthermia}

Currently, HT is obtained via magnetic induction, and is a technique indicated for the destruction of cancer cells with the use of a magnetic field. Magnetic particles may reach the cancer cells through direct intra-tumoral injection or introduced in the bloodstream and magnetically driven into the tumor site [30]. Once in the tumor, the magnetic material is heated by an external alternating magnetic field (due to magnetic loss processes), hopefully leading to the destruction of malignant cells, whereas most of the surrounding healthy tissue remains relatively unaffected [31]. The typical increase of temperature of cancerous tissue is within $42-46^{\circ} \mathrm{C}$ [31], by hysteresis heat loss of ferromagnetic materials. The temperature increase results in ischemic necrosis that leads to cancer cell destruction [17]. 
The main advantage of this technique is the ability to treat cancer locally, potentially without any dangerous systemic effect. Other important feature is the fact that the procedure is minimally invasive, being appropriate for the treatment of cancer tumors in sensitive regions of the body, as lung and brain [30]; this is important to ensure that the patient is as comfortable as possible during the treatment. Finally, unlike chemotherapy, whose drugs cause severe side effects on healthy organs, and radiotherapy, which severely affects the surrounding tissue, HT has mild side effects and has been shown to have a synergistic effect with many of the traditional treatment modalities [3].

\section{Basics of magnetic properties}

The use of magnetic materials poses technical problems for HT therapy, such as the difficulty to uniformly heat the tumor region up to the required temperature without damaging the surrounding healthy tissue [32]. The control of magnetic properties plays a crucial role in understanding heat generation and temperature distribution within the tissue by magnetic induction hyperthermia [33]. Therefore, we shortly discuss the main magnetic properties.

\subsection{Ferro- and ferrimagnetic materials}

The magnetic properties of matter originate from the magnetic moments of the electrons located in the incomplete layers in the atoms $3 \mathrm{~d}$ orbital; in the case of transition metal group elements, $4 \mathrm{f}$ orbital in rare earth, and the unpaired electrons in the conducting band. The magnetic materials that exhibit spontaneous magnetization below a certain critical temperature, defined as Curie temperature (Tc) are the ferromagnetic and ferrimagnetic materials [36]. Above Tc there is a phase transition representing a break in the symmetry of magnetic moments, causing no further spontaneous magnetization, and as a consequence, a disordered paramagnetic phase appears. Ferromagnetic materials present an ordering lattice of parallel magnetic moments, while ferrimagnetic materials exhibit two sublattices with different magnetic moments aligned in an antiparallel way and show that a total magnetic moment is nonzero.

When ferromagnetic or ferrimagnetic materials are submitted to an intense magnetic field, small regions defined as magnetic domains are established, and the boundaries between them are called domain walls. The inner of each magnetic domain magnetization (sum of all magnetic moments/volume) has the same orientation as the applied magnetic field when the material has a linear response.

The main feature ferromagnetic and ferrimagnetic materials is the existence of a magnetic hysteresis curve that is associated with the orientation of magnetic domains. When an external magnetic field is applied $(\mathrm{H})$, the magnetic moments tend to orient in the direction of the magnetic field [34]. Figure 3 shows the magnetization behavior $(\mathrm{M})$ as a function of the applied magnetic field, $(\mathrm{MxH}$ curve). At the beginning of the magnetization process, it increases [1] with an increase in the magnetic field, up to a maximum value called saturation magnetization $(+\mathrm{Ms})$ in the saturation field. After this process, magnetic field $\mathrm{H}$ decreases, and as a consequence, $\mathrm{M}$ decreases more slowly to the residual value of magnetization [2], called the

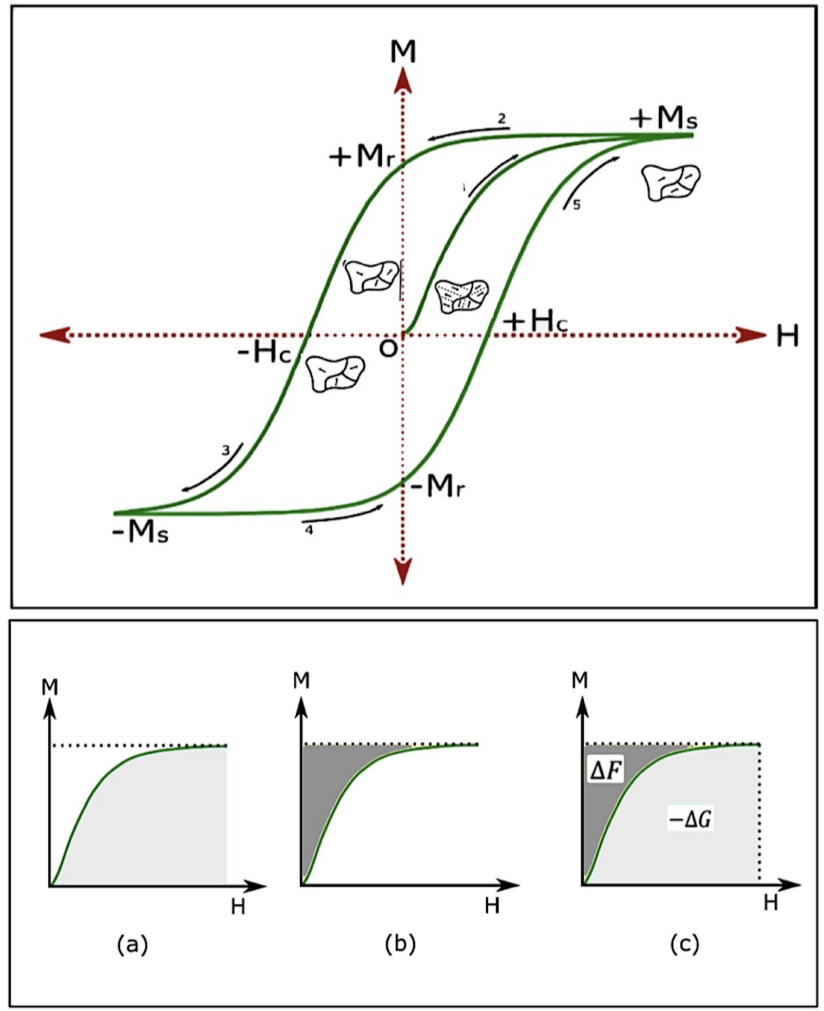

Figure 3: Top figure - Hysteresis loop; initially the sample exhibit in an demagnetized state. Magnetization appears as an imposed magnetic field $\mathrm{H}$, modifies and eventually eliminates the microstructure of ferromagnetic domains magnetized in different directions, to reveal the spontaneous magnetization Ms. The remanence $\mathrm{Mr}$ which remains when the applied field is restored to zero, and the coercivity $\mathrm{Hc}$, which is the reverse field needed to reduce the mag netization to zero, are indicated on the curve. Bottom figure - (a) magnetic losses due to changes of direction of magnetic domains; (b) Shaded area associated with the work of the magnetization process and (c) Free energies associated with changes of Helmholtz (F) and Gibbs (G) energies of the reversible process of the magnetization curve [34]. 
remnant magnetization $(+\mathrm{Mr})$, where the magnetic field is null, and the material exhibits a spontaneous magnetization. Reversing the magnetic field direction, the magnetization continues to decrease to zero. The specific field value where this occurs is called the coercive field (-HC). If the field [3] continues to decrease, the magnetization exhibits a minimum, i.e., a negative saturation region $\left(-\mathrm{M}_{S}\right)$ The process and repeating the cycle in the opposite direction lead to a closed curve, which is the magnetic hysteresis curve.

The hysteresis loop presents information on intrinsic magnetic characteristics of a material, as the spontaneous magnetization Ms, which exists within a domain of a ferromagnet. Moreover, there are two extrinsic properties, the remanence $\mathrm{Mr}$ and coercivity $\mathrm{Hc}$, which depend on many external factors as the sample shape, surface roughness, microscopic defects and thermal history, as well as the rate at which the field is swept in order to trace the loop.

Figure 3 shows details of changes in the magnetic energy in the hysteresis cycle. In (a), we can observe the magnetic losses due to changes of direction of magnetic domains and (b) the work associated to magnetization processes, and in (c) Free energies associated with changes of Helmholtz $(\mathrm{F})$ and Gibbs $(\mathrm{G})$ energies of the reversible process of the magnetization curve.

\subsection{Superparamagnetism}

From the point of view of applications of ferromagnetic/ferrimagnetic in magnetic-induced hyperthermia, it is important that the material presents a significantly magnetic hysteresis to optimize the transference of magnetic energy to heat. An alternative to optimizing the heat transfer process is to increase the contact area between the magnetic material within the composite in the form of small particles. However, when the size of the magnetic particle is reduced, the magnetic anisotropy energy competes with the thermal energy so that there is a minimum volume at which the particle still remains blocked. This limit is called the superparamagnetic limit.

The magnetostatic energy and magnetocrystalline anisotropy energy contributes to the formation of magnetic domains [35]. In a first approximation, the magnetostatic (dipole-dipole) energy is inversely proportional to the volume of the particle $\left(\mathrm{R}^{3}\right)$, and the domain wall energy is proportional to the area of the wall $\left(\mathrm{R}^{2}\right)$. By looking at the balance between the magnetostatic energy and the domain wall energy, it is energetically unfavorable to form domain walls below a critical radius, because the domainwall energy is shallow, and a single domain is created as a result of high magnetostatic energy. For a sphere containing two semi-sphere domains of opposite magnetization with axial magnetic anisotropy, the critical single-domain radius $\left(\mathrm{R}_{C}\right)$ is given by Eq. (1) [36].

$$
R_{C}=\frac{36 A K_{1}}{\mu_{0} M_{S}^{2}}
$$

$A$ is the exchange stiffness, $K_{1}$ is an anisotropy constant, $\mu_{0}$ is the magnetic permeability of the free space and $M_{s}$ is the saturation magnetization.

If the particle size is below the critical radius $\mathrm{R}_{C}, \mathrm{Hc}$ decreases to zero, and as a consequence, when Hc reaches zero, it means that the particles will magnetize in the presence of an external magnetic field and revert to a nonmagnetic state when the magnetic field is removed. In this situation, magnetization can randomly flip direction under the influence of temperature. The time between two flips is called the Néel relaxation time. In the absence of an external magnetic field, the time used to measure the magnetization of the nanoparticles is much longer than the Néel relaxation time (in order of seconds). In this case, the magnetization appears to be in average zero, characterized as superparamagnetic state, and presents a behavior similar to paramagnet; however, the magnetic susceptibility is much larger than that of paramagnets (in order of thousands bohr magnetons).

Another important characteristic of superparamagnetic behavior is the measurement time $\tau_{m}$. When the measurement time is much less than the Néel relaxation time $\left(\tau_{m} \ll \tau_{N}\right)$, a blocked state occurs. As a consequence, the magnetization measurement is just the instantaneous magnetization at the beginning of the measurement because there was no direction flip. In this state, the nanomaterials behave like a normal paramagnet but with a much higher susceptibility.

When the measurement time is much greater than the Neel relaxation time $\left(\tau_{m} \gg \tau_{N}\right)$, this results in the superparamagnetic state in which the net moment is zero due to the fluctuations in magnetization. If we consider typical time for measurements in the order of $100 \mathrm{~s}$, the blocking temperature is estimated by equation 2 :

$$
T_{B}=\frac{K V}{k_{B} \ln \left(\frac{\tau_{m}}{\tau_{m}}\right)},
$$

where $K$ is the anisotropy constant and $k_{B}$ is the Boltzmann constant.

\subsection{Heat generation mechanism}

For multidomain Ferro- or ferrimagnetic materials, heating is due to hysteresis losses. Indeed, large particles of 
such materials contain several sub-domains, each of them having a definite magnetization direction. When exposed to a magnetic field, the domain with magnetization direction along the magnetic field axis grows, and the other ones shrink. This phenomenon is called 'domain wall displacements'.

From the magnetization curve as a function of the applied magnetic field, it is possible to calculate the work performed by the magnetic field on the ferromagnetic/ferrimagnetic material. Magnetic work $\left(E_{m a g}\right)$ is expressed in terms of the equation 3:

$$
E_{\text {mag }}=\int_{0}^{M} \mu_{0} H_{\text {ext }} d M
$$

Magnetic work is associated with the processes and losses on the magnetic hysteresis curve, as shown in Figure 3 where the shaded area below the curve represents the magnetic losses of the closed hysteresis cycle, and the area above the curve represents the work required to orient the magnetic domains towards the magnetic field, causing the sample to remain magnetized. As this phenomenon is not reversible, i.e., magnetization curves for increasing and decreasing the magnetic field amplitudes do not coincide, the material is said to exhibit a 'hysteresis behavior' and produces heat under an AC magnetic field.

In single-domain particles, which exhibit superparamagnetism, no heating due to hysteresis losses can occur because there is no domain wall.

The release of heat in a magnetic material is based on Neel and Brownian relaxations. In the presence of an external alternating magnetic field, the magnetic moment rotates, and the nanoparticle itself rotates and then relaxes back to their original magnetic field orientation. The rotation of the magnetic moment (Néel mode) and the friction arising from particle oscillations (Brownian method) leads to a phase lag between the applied magnetic field and the direction of the magnetic moments. As a result, the heat is released.

For tiny particles, the Néel mode is predominant; for larger particles, however, the heat generation is mostly due to a combination of Brownian rotation (or Brownian relaxation loss) and hysteresis loss. For coarse particles or rods, heat generation is mainly due to hysteresis loss. More details regarding the mechanisms of heat generation can be found in the reference [36]. When the loop area is larger, it will generate efficient magnetic work to move the magnetic domains. The modification of the internal energy and entropy occurs for the first law of thermodynamics in a process at a constant temperature. In the case of hyperthermia, the process is more dependent on the applied fre- quency than the hysteresis loop, since the amplitude of the AC field is small. Thus, the most important aspect is the frequency variation.

The efficiency of heating is measured regarding the specific absorption rate (SAR) or particular loss of power (SLP), which is defined as the power of heating a magnetic material per gram (Eq. (3)). For biomedical applications, the value of SAR is critical, since the higher the specific absorption rate, the lower the quantity of material needed.

$$
S A R \text { or } S L P(\mathrm{~W} / \mathrm{g})=\frac{C}{m} \frac{\Delta T}{\Delta t}
$$

Where $C$ is the specific heat capacity of the sample $(\mathrm{J} / \mathrm{g} \cdot \mathrm{K})$, $m$ is the mass of magnetic particles and $\Delta T / \Delta t$ is the initial slope of temperature versus time dependence. When particles are dispersed in a gel or a liquid, contribution of specific heat capacities of the surrounding media must be taken into account.

It is tough to give a general theoretical expression of SAR because of a large number of parameters: size, size distribution, shape and chemical composition of particles, frequency, and amplitude of the magnetic field, etc. For example, the specific absorption rate due to hysteresis losses (SARH) is proportional to product $\mathrm{A}^{\star} \nu$, where $\mathrm{A}$ is the area of the hysteresis cycle and $v$ is the frequency for maximal heating [13].

It is known that SAR strongly depends on the Ms, as well as the volume fraction and particle size of the material present. High Ms values are required to increase the temperature of tumor cells above $42^{\circ} \mathrm{C}$. Considering the strong dependence of the SAR on the magnetic properties such as saturation magnetization, physical parameters like composition, size, and shape can be engineered to enhance the heat generation and minimize the quantity of material to be used.

\section{Materials used for magnetic-induced hyperthermia}

Many magnetic materials can be used for heat generation and dissipation for HT therapy $[11,13]$. To the best of our knowledge, the first research on the use of magnetic materials for this purpose was carried out in 1957 by Gilchrist $e t$ al. [16], which developed a methodology for heating the tissue samples with $\gamma-\mathrm{Fe}_{2} \mathrm{O}_{3}$ particles exposed to a magnetic field of $1.2 \mathrm{MHz}$ [16].

Since Gilchrist, numerous studies have reported on different methodologies and magnetic materials, magnetic fields, frequencies and methods of encapsulation [11, 
13, 17]. Among the iron oxides, magnetite $\left(\mathrm{Fe}_{3} \mathrm{O}_{4}\right)$ and maghemite $\left(\gamma-\mathrm{Fe}_{2} \mathrm{O}_{3}\right)$ are popular because they exhibit magnetic properties that are suitable for biomedical applications. Magnetite is, by far, the most widely used material in magnetic HT therapies. The features and applications of magnetite and maghemite have been extensively reviewed $[13,30,36,38,39]$. Most studies report on the utilization of nanometric particles (from 3 up to $350 \mathrm{~nm}$ ), with Ms values from 10 to $90 \mathrm{emu} / \mathrm{g}$, and SAR values ranging from 0.1 to $600 \mathrm{~W} / \mathrm{g}$.

There are tree methods to obtain iron nanoparticles: physical methods, chemical preparation methods and biological methods. Among these methodologies, chemicalbased synthesis methods are mostly adopted due to low production cost and high yield. $\mathrm{Fe}_{3} \mathrm{O}_{4}$ or $\alpha-\mathrm{Fe}_{2} \mathrm{O}_{3}$ can be synthesized through the co-precipitation of $\mathrm{Fe}^{2+}$ and $\mathrm{Fe}^{3+}$ aqueous salt solutions by addition of a base. The control of size, shape, and composition of the nanoparticles depends on the type of salt used (e.g., chlorides, sulfates, nitrates, perchlorates, etc.), $\mathrm{Fe}^{2+}$ and $\mathrm{Fe}^{3+}$ ratio, $\mathrm{pH}$ and ionic strength of the solution media [38]. In general, magnetites are synthesized by adding a base to an aqueous mixture of $\mathrm{Fe}^{2+}$ and $\mathrm{Fe}^{3+}$ chloride at 1:2 molar ratio, resulting in black color [40]. There are some products commercially available; for example MP25 series (Nanocs), nanomag ${ }^{\circledR}$ (micromod Partikeltechnologie $\mathrm{GmbH}$ ), siennova ${ }^{\circledR}$ (Endomag) and magno (nB NanoScale Biomagnetics).

Another option for cancer HT is iron metal (Fe), which has higher magnetization than magnetite and maghemite. However, Fe is highly susceptible to oxidation, which limits its use in biomedical applications. Metallic alloys, such as Fe-Pt, $\gamma$-Fe-Ni, Fe-Co-Ni, Ni-Cu, Ni-Si, Ni-Co, and Pd-Co have also been used in magnetic HT [13, 41, 42]. However, alloying elements, such as nickel and cobalt, are toxic and susceptible to oxidation, even though they exhibit a high magnetic moment. A poor corrosion resistance characterize these alloys, and their resulting thermoseeds often require a protective coating layer [41]. It is worth noting that these metal ions may induce tissue toxicity due to their ability to be internalized, thereby initiating oxidative stress, which causes inflammation [43]. Moreover, some metallic alloys require very high magnetic fields, being out of the medical practice.

Ferrites having the spinel crystal structure $\left(\mathrm{M}-\mathrm{Fe}_{2} \mathrm{O}_{4}\right.$, where $\mathrm{M}=\mathrm{Mn}, \mathrm{Ni}, \mathrm{Co}, \mathrm{Zn}$ ) can also be used for cancer HT. Their magnetic properties can be altered without affecting the crystalline structure substantially; in this case, the resulting property will depend on the nature of the cation and its relative distribution in the tetrahedral and octahedral sites. Lee et al. [44], for example, found that $\mathrm{MnFe}_{2} \mathrm{O}_{4}$ has a higher Ms $(110 \mathrm{emu} / \mathrm{g})$ when compared to other fer- rites, such as $\mathrm{FeFe}_{2} \mathrm{O}_{4}(101 \mathrm{emu} / \mathrm{g}), \mathrm{CoFe}_{2} \mathrm{O}_{4}(99 \mathrm{emu} / \mathrm{g})$ and $\mathrm{NiFe}_{2} \mathrm{O}_{4}$ MNPs $(85 \mathrm{emu} / \mathrm{g})$. Despite their low solubility, the release of free metal ions can induce toxicity and affect cell cycle as well as cell proliferation. The accumulation of cobalt ions, for example, has a genotoxic effect and may cause an inflammatory response, and even tissue necrosis [36].

\section{Nanoparticles in magnetic HT: the only solution?}

Nanoparticles exhibit different physical and chemical properties in the macro and atomic level. For instance, iron oxide-based nanoparticles become superparamagnetic at room temperature when their size is below about $15 \mathrm{~nm}$ [45]. Superparamagnetic nanoparticles are of interest because do not retain magnetism after the removal of the magnetic field. That means below $15 \mathrm{~nm}$ remanent magnetization is not observed.

The reason because the nanoparticles are so attractive is the possibility of injecting them intravenously, making HT therapy minimally invasive. Besides hyperthermia, magnetic nanoparticles have also been utilized in cellular labeling, drug delivery, magnetic resonance imaging and magnetofection. The use of nanoparticles, however, is accompanied by several limitations. The saturation magnetization in iron-oxide nanoparticles, for example, is usually smaller (30-50 emu/g) when compared to the bulk material $(90 \mathrm{emu} / \mathrm{g})$, this has been attributed to the presence of defects at the surface of the nanoparticles, and reduces the magnetization [38]; at this level, where the specific surface area is enormous, the presence of superficial defects become critical.

Moreover, magnetic nanoparticles have complex fabrication routes [46]. Because of the small size, iron oxidebased nanoparticles tend to agglomerate readily. Therefore, these particles are coated against agglomeration by either non-magnetic or magnetic shells [47]. In general, the coatings have three primary functions: (1) enhance the colloidal stability, (2) prevent oxidation and (3) make them biocompatible or allow for surface functionalization. The type of coating used can lead to a negative impact on the heating efficiency of the core since the surface properties are modified. Studies have shown that coating magnetic particles with non-magnetic material, e.g., $\mathrm{Fe}_{3} \mathrm{O}_{4}$ coated with $\mathrm{SiO}_{2}$ [48], will decrease the Ms (from $72 \mathrm{emu} / \mathrm{g}$ to 37 $\mathrm{emu} / \mathrm{g}$ ) and hence cause a reduction of around $26 \%$ in the SAR value (from 1.5 to $1.1 \mathrm{~W} / \mathrm{g}$ ), when compared with uncoated particles. The decrease in Ms was attributed to the 
enhanced surface spin effects, and thus not all the core material contributes to the Ms.

Another significant obstacle still is the successful implantation into a particular site in the body. For example, in a very early in vivo study using Sprague Dawley rats, Gordon et al. [49] identified a fraction of the injected nanoparticles allocated outside the tumor, in the liver, spleen, and kidney. Another relevant issue related to the clinical use of nanoparticles is that the host immune system can phagocyte these nanoparticles, preventing them from reaching the target and decreasing the effectiveness of the HT therapy [50]. When it is difficult to reach the tumor, the treatment may not be plausible or effective [51-54]. There are concerns about the possibility of nanoparticles reaching the damaged tissue [55]. While the external magnetic field can guide the nanoparticles flow to the target cells, the organic and inorganic molecules in the body can bind on the nanoparticles surface and trap them from reaching the target area [56].

The effectiveness of nanoparticles in eliminating tumors is questionable. Based on a theoretical model, Rabin [57] demonstrated that nano-scale heating effects are negligible, which indicates that a single magnetic nanoparticle has no effect on hyperthermia. The most conservative calculation suggested that the region occupied by nanoparticles must be at least $1.1 \mathrm{~mm}$ in diameter, to reach the threshold for hyperthermic conditions. This value is expected to increase considerably in the presence of blood flow. This value of minimum diameter is at least two orders of magnitude larger than the size of a typical cancer cell. This study indicates that a considerable volume of material is needed to reach the amount of heat necessary to kill tumors; this can be achieved by using a significant amount of nanoparticles or a smaller amount of larger particles (in the micron or submicron scale). According to Borrelli et al. [58], particles should be at least $1 \mu \mathrm{m}$ in size to allow for domain wall motion, and therefore, cause significant heating by hysteresis loss.

Most important is that considering that iron oxide nanoparticles could successfully help to eliminate a tumor, their ability to regenerate tissues is absent. In the case of bone cancer, frequently a large void is generated after tumor curettage, causing bone weakening. Furthermore, even after the removal of a tumor, the malignant cells may remain around the tumor site, resulting in tumor recurrence. In this case, magnetic bioactive glass or glassceramic particles may be subjected to a reheating process, when necessary, to kill newly born cancerous cells to prevent tumor recurrence. Additionally, the leaching of (potentially harmful) metal ions in the human body fluid by such materials can be avoided due to the encapsulation of each ferromagnetic particle by the glass matrix [9].

\section{Glass-ceramics and their advantages}

Initially designed to bond to bone, bioactive glasses have encountered a broad range of applications in tissue engineering [59]. Some particular compositions were found to bond to both hard (bone) and soft tissues (skin, nerve, ligaments, etc.) [60], as well as stimulate their regeneration. The most striking features of bioactive glasses are osteoconductivity and osteoinductivity, ability to bond to soft tissues, angiogenic potential, and antibacterial properties [61-63].

Despite their attractive properties, bioactive glasses lack the desirable magnetic properties, displayed only by ferri- and ferromagnetic crystalline phases. To combine bioactivity, solubility, and magnetic properties in the same material is a challenging task. In order to overcome this, glass-ceramics may be the suitable solution. Glassceramics are polycrystalline materials produced by the controlled crystallization of glasses. According to the updated definition proposed by Deubener et al. [64], "glassceramics are inorganic, non-metallic materials prepared by controlled crystallization of glasses via different processing methods. They contain at least one type of functional crystalline phase and a residual glass. The volume fraction crystallized may vary from ppm to almost 100\%" [sic] [64]. Since their accidental discovery by Stookey in the early 1950's, glass-ceramics gained scientific importance and had been used in several commercial applications. The conventional way to synthesize a glass-ceramic is the melt-quenching technique, followed by a single or double-stage heat treatment, providing the nucleation and growth of specific crystalline phases. The phase(s) present, the crystallized fraction, the nano- or microstructure, and therefore the material's properties, can be tailored for specific purposes [63].

As mentioned in the previous section, the success of any cancer treatment therapy is measured by the capability to eliminate the cancer cells entirely. This goal has to be achieved while the irreversible damage in the healthy tissue should be minimized, preserving its functionality. The regeneration of normal tissues depends on the number of stem cells that have survived the treatment. In several cases, mainly when a tumor is removed, a large volume of tissue is lost. A dramatic problem, particularly for tissues with low cell proliferation rates. Some bioactive 
glass compositions are not only able to foster regeneration of both hard and soft tissues but can stimulate the growth of new blood vessels, i.e., they are angiogenic. Those are mandatory condition to recover the damaged tissue. Therefore, the combination of crystals with controlled size and exhibiting ferromagnetic properties embedded in a bioactive glassy matrix represents an underexplored but promissory alternative for cancer treatment by HT.

A search on Web of Science database with the keywords "glass-ceramic", "cancer" and "hyperthermia" (topic search - April 2017) returned only 75 publications, including one patent. Maybe the large number of papers on iron-oxide nanoparticles and their relative success in HT has discouraged research and further developments of glass-ceramics for the same purpose.

The first reference on a magnetic glass-ceramic intended for the treatment of cancer is a patent from Corning Glass Works dated from 1981 [58], Borrelli, Luderer, and Panzarino, the inventors and researchers at Corning by that time, described biocompatible glass-ceramics containing iron. This patent covered a wide range of compositions, but mainly iron phosphate glass-ceramics (with considerable amounts of $\mathrm{SiO}_{2}$ and $\mathrm{B}_{2} \mathrm{O}_{3}$ ), containing magnetite or ferrites (specifically $\mathrm{Li}, \mathrm{Co}, \mathrm{Ni}, \mathrm{Mn}$ and $\mathrm{Ba}$ ferrites) as the magnetic phase. All the compositions tested partially crystallized upon cooling; however, the volume crystallized fraction, and the average crystal size could be increased through appropriate heat treatments.

Two years later, in 1983, Luderer et al. [65] published the very first paper reporting the use of a glass-ceramic for magnetic cancer hyperthermia. Luderer already glimpsed the advantages of glass-ceramics: "The reason for using a glass-ceramic material as opposed to a pure ferrimagnetic ceramic material was that much greater control could be exercised over the physical, chemical, biochemical, and magnetic properties of the glass-ceramic by glass composition, glass-forming technique, and thermal history." Luderer et al. [66] described a biocompatible lithium iron phosphate $\left(11.6 \mathrm{Li}_{2} \mathrm{O}-0.4 \mathrm{Al}_{2} \mathrm{O}_{3}-3.4 \mathrm{SiO}_{2}-23.7 \mathrm{P}_{2} \mathrm{O}_{5}-60.5 \mathrm{Fe}_{2} \mathrm{O}_{3}\right.$, it was not informed if $\mathrm{wt} \%$ or mol\%) composed of hematite and lithium-ferrite as main crystalline phases. The glassceramic was milled to a $1.5 \mu \mathrm{m}$ average size and tested against a breast carcinoma tumor in vivo, in a subcutaneous rat model. This material generated an Ms of 8.69 $\mathrm{emu} / \mathrm{g}(10 \mathrm{kG})$ and a SAR of approximately $1 \mathrm{~W} / \mathrm{g}$ (500 Oe, $10 \mathrm{kHz}$ ), allowing a local temperature rise of $\sim 9^{\circ} \mathrm{C}$ (maximum $\mathrm{T}=43.5^{\circ} \mathrm{C}$ ) after 7 minutes. Approximately $12 \%$ of all animals subjected to the treatment with this glass-ceramic were considered cured. Additionally, 50\% of the animals had no detectable tumor after five days, survived longer than their contemporary controls but died due to tumor re- currence. In this latter group, tumor regrowth was always observed at the margin of the original tumor, indicating that the thermal dose was insufficient. Nevertheless, this can be considered a successful result, if one considers that all animals were subjected to a single-heating procedure.

Years later, many other papers reporting the development and characterization of glass-ceramics intended for cancer HT were published. In the next section, it is presented a review of the published documents within this subject in the past 35 years. The publications were grouped according to the type of magnetic phase obtained. Afterward, the main in vitro and in vivo findings are also addressed.

Milling of iron oxide nanoparticles in air may lead to oxidation [38]. On the other hand, in a situation where magnetic nanocrystals are "trapped" in a glassy matrix, the oxidation would be prevented.

\subsection{Magnetite-based glass-ceramics}

As it would be expected, magnetite-containing glassceramics are the most studied material of this class intended for cancer hyperthermia [10, 67, 68].

Seven years after Luderer, in 1990, Kokubo [69] was the first to demonstrate the possibility of both bioactive and magnetic glass-ceramic. At that time, the $\mathrm{A} / \mathrm{W}$ glass-ceramic was already worldwide known for its bioactivity and high mechanical strength. Thus, based on A/W, Kokubo developed a $\mathrm{P}_{2} \mathrm{O}_{5}$-free calcium silicate, with composition $40 \mathrm{Fe}_{2} \mathrm{O}_{3}-60\left(\mathrm{CaO}-\mathrm{SiO}_{2}\right)$ (wt \%). After heattreatment, the glass-ceramic was composed of magnetite nanocrystals, $\beta$-wollastonite, and a residual glassy phase.

Using the same composition developed by Kokubo, Ebisawa et al. [70] performed further studies. They demonstrated that the crystallized volume fraction of magnetite is higher than $30 \%$ for heat-treatments performed at high temperatures $\left(\mathrm{T}>950^{\circ} \mathrm{C}\right)$. The Ms increased linearly with the volume fraction of magnetite, reaching a maximum of approximately $30 \mathrm{emu} / \mathrm{g}$ (Figure $4-4 a$ ). It is interesting to note that if one extrapolates the line to a crystallized fraction of $100 \%$, Ms would be approximately $90 \mathrm{emu} / \mathrm{g}$; this is the same value reported for pure magnetite pow$\operatorname{der}(\sim 92 \mathrm{emu} / \mathrm{g})$, this revealed that the magnetite crystallized from the calcium-silicate glass has the same magnetization of pure magnetite. The size of magnetite crystals may increase from $6 \mathrm{~nm}$, for a heat-treatment performed at $700^{\circ} \mathrm{C}$, to about $110 \mathrm{~nm}$, for a heat-treatment performed at $1050^{\circ} \mathrm{C}$. Interestingly, the glass-ceramic having magnetite crystals larger than $20 \mathrm{~nm}$ showed a coercive force (Hc) higher than that of pure magnetite crystals of the same 
size (Figure $4-4 b)$. In the case of the glass-ceramic, the Hc reached a maximum value $(\sim 500 \mathrm{Oe})$ for a crystal size of $40 \mathrm{~nm}$. Ebisawa et al. attributed the higher values of the coercive field in the glass-ceramic to the fact that the crystals in the glassy matrix are under stresses caused by the difference regarding thermal expansion coefficient. Thus, such internal stress level must have inhibited rotation of the magnetic moment, increasing Hc. It is not clear why there is a maximum value of $\mathrm{Hc}$ for a crystal size of $40 \mathrm{~nm}$ According to the authors, Hc initially increases with crystal size due to the increasing ordering of the magnetic moment. A single domain is formed at $40 \mathrm{~nm}$; above $40 \mathrm{~nm}$, the number of domains in a single crystal increases, decreasing the coercive field [70].
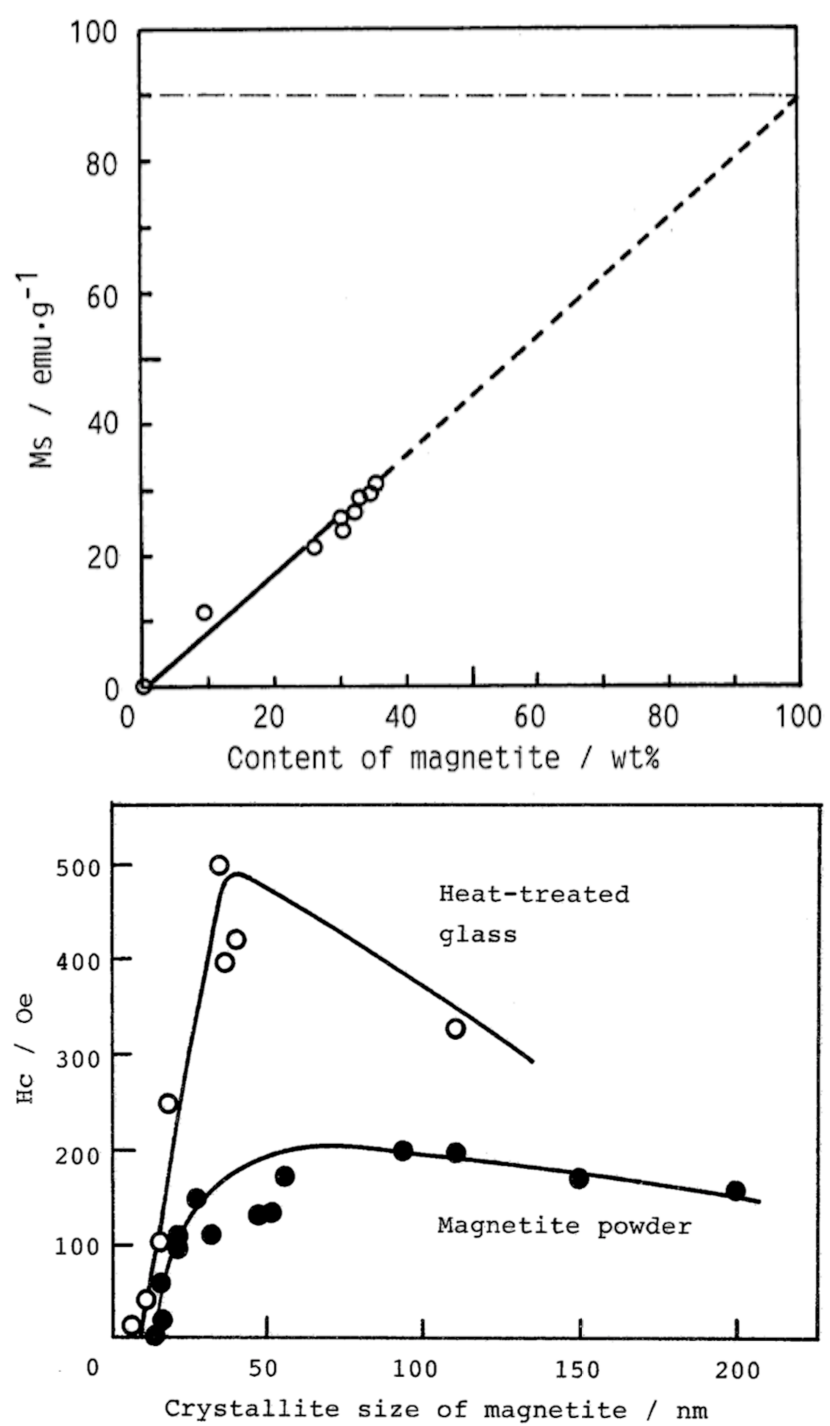

Figure 4: Saturation magnetization (Ms) as a function of magnetite content (a) and coercive field $(\mathrm{Hc})$ as a function of magnetite crystal size, in the $40 \mathrm{Fe}_{2} \mathrm{O}_{3}-60\left(\mathrm{CaO}-\mathrm{SiO}_{2}\right)(\mathrm{wt} \%)$ glass-ceramic. Figures extracted from reference [70].
In their later study [71], the same authors showed that their glass-ceramics were bioactive if small amounts of $\mathrm{Na}_{2} \mathrm{O}, \mathrm{B}_{2} \mathrm{O}_{3}$ and/or $\mathrm{P}_{2} \mathrm{O}_{5}$ are added into the parent glass [71]. In a different work [72], this research group studied in vitro bioactivities of ferrimagnetic glassceramics with the compositions $60\left(\mathrm{CaO}-\mathrm{SiO}_{2}\right)-40(\mathrm{FeO}$, $\mathrm{Fe}_{2} \mathrm{O}_{3}$ ) (wt $\%$ ), having $3 \% \mathrm{Na}_{2} \mathrm{O}, \mathrm{B}_{2} \mathrm{O}_{3}$ and/or $\mathrm{P}_{2} \mathrm{O}_{5}$. They found that glass-ceramics containing $\mathrm{Na}_{2} \mathrm{O}$ or $\mathrm{B}_{2} \mathrm{O}_{3}$ in combination with $\mathrm{P}_{2} \mathrm{O}_{5}$ are bioactive. The results mentioned above show that glass-ceramics of the $\mathrm{FeO}-\mathrm{Fe}_{2} \mathrm{O}_{3}$ $\mathrm{CaO}-\mathrm{SiO}_{2}$ system can exhibit bioactivity as well as ferrimagnetism, by a small addition of certain oxides [72].

In the work of Masakazu et al. [73] the glass ceramic containing magnetite prepared by heat treatments of a $40 \mathrm{Fe}_{2} \mathrm{O}_{3}-29 \mathrm{CaO}-31 \mathrm{SiO}_{2}-3 \mathrm{P}_{2} \mathrm{O}_{5}$ (weight ratio) glass in $90 \mathrm{CO}_{2}+10 \mathrm{H}_{2}$ atmosphere. The crystallite size and fraction of magnetite increasing heat treatment temperature to reach about $150 \mathrm{~nm}$ and $36 \mathrm{mass} \%$ at $1150^{\circ} \mathrm{C}$, respectively. The glass showed magnetic response and properties for the hyperthermia treatment of cancer. The work does not present studies of biocompatibility.

In the study carried out by Seung-Han Oh et al. [32] in 2001, the heat-generating power of ferrimagnetic $\mathrm{CaO}$ $\mathrm{SiO}_{2}-\mathrm{Fe}_{2} \mathrm{O}_{3}$ glass-ceramics was improved by avoiding the appearance of undesired non-magnetic crystalline phases, and by restriction of magnetite oxidization during heat treatment. For this purpose, the crystallization heat treatment was fixed above $880^{\circ} \mathrm{C}$. Also, addition of $1 \%$ of $\mathrm{P}_{2} \mathrm{O}_{5}$ and $\mathrm{B}_{2} \mathrm{O}_{3}$ as a viscosity reducer in $30 \mathrm{CaO}-30 \mathrm{SiO}_{2}-40 \mathrm{Fe}_{2} \mathrm{O}_{3}$ (wt \%) glass-ceramics led to a decrease the optimal crystallization temperature of magnetite from $1000^{\circ} \mathrm{C}$ to $940^{\circ} \mathrm{C}$. Since the magnetite crystal is easily oxidized above $900^{\circ} \mathrm{C}$ under air atmosphere, these additives can be helpful to suppress the oxidation [32]. The maximum nucleating and crystal growth rates were $20.47 \times 10^{6} / \mathrm{mm}^{2} \cdot \mathrm{s}$ at $690^{\circ} \mathrm{C}$ and $8.125 \mathrm{~nm} / \mathrm{min}^{0.5}$ at $940^{\circ} \mathrm{C}$, respectively. After nucleation at $690^{\circ} \mathrm{C}$ for $60 \mathrm{~min}$ before crystal growth at $940^{\circ} \mathrm{C}$ for $2 \mathrm{~h}$, samples exhibited the following properties: crystallite size of $90.5 \mathrm{~nm}$, the maximum volumetric fraction of $31.1 \%$, and saturation magnetization of $100 \mathrm{emu} / \mathrm{cm}^{2}$. The coercive field were ranged between 382.0 and 388.2 Oe in all heat-treatment conditions. Moreover, it is shown from the results of a preclinical evaluation of biocompatibility, by the agar diffusion test with L929 cells, that both asquenched and heat-treated glasses were considered biocompatible [32].

Eniu et al. [74] investigated the structural effects caused by iron addition to glasses in the $\mathrm{xFe}_{2} \mathrm{O}_{3}$ 45(3.34CaO- $\left.\mathrm{P}_{2} \mathrm{O}_{5}\right)(55-\mathrm{x}) \mathrm{SiO}_{2}$ system and the magnetic properties of the corresponding glass-ceramics. In this system, both $\mathrm{SiO}_{2}$ and $\mathrm{P}_{2} \mathrm{O}_{5}$ are glass formers while $\mathrm{CaO}$ and 
$\mathrm{Fe}_{2} \mathrm{O}_{3}$ act as glass network modifiers. DTA measurements showed that the glass transition temperature increases by the addition of iron up to $20 \mathrm{~mol} \%$. After heat treatment, the iron preponderantly crystallizes as magnetite $\left(\mathrm{Fe}_{3} \mathrm{O}_{4}\right)$, but hematite $\left(\alpha-\mathrm{Fe}_{2} \mathrm{O}_{3}\right)$ and maghemite $\left(\gamma-\mathrm{Fe}_{2} \mathrm{O}_{3}\right)$ are also developed. $\alpha-\mathrm{Fe}_{2} \mathrm{O}_{3}$ showed a very low saturation magnetization $\left(0.4 \mathrm{~A} \cdot \mathrm{m}^{2} / \mathrm{kg}\right)$ as compared with $\mathrm{Fe}_{3} \mathrm{O}_{4}(90-92$ $\mathrm{A} \cdot \mathrm{m}^{2} / \mathrm{kg}$ ), while the saturation magnetization of $\gamma-\mathrm{Fe}_{2} \mathrm{O}_{3}$ $\left(80 \mathrm{~A} \cdot \mathrm{m}^{2} / \mathrm{kg}\right)$ is close to that of magnetite. According to the EPR results, the iron ions seem to form low-sized magnetic domains, even in glass samples. The magnetization measurements in function of magnetic field and temperature indicate a ferrimagnetic behavior with the Curie temperature $\left(\mathrm{T}_{c}\right)$ around $820 \mathrm{~K}$ for the investigated samples.

In 2005, Leventouri et al. [75] prepared ferromagnetic bioactive glass-ceramics in the system $\mathrm{CaO}-\mathrm{SiO}_{2}-\mathrm{P}_{2} \mathrm{O}_{5}$. $\mathrm{Na}_{2} \mathrm{O}-\mathrm{Fe}_{2} \mathrm{O}_{3}$ by a melting method, the melting process in an electric furnace, in a crucible at at $800^{\circ} \mathrm{C}$ for $3 \mathrm{~h}$ of calcination, it was held for the melting process for $30 \mathrm{~min}$. The melt was quenched by pouring onto a stainless steel plate at room temperature. Subsequently, pieces from the four samples series were heat-treated in air for $6 \mathrm{~h}$ at temperatures between 600 and $1100^{\circ} \mathrm{C}$. They have shown that the magnetic properties of these glass-ceramics, vary with the processing parameters, like Ms, Hc, and $\mathrm{Mr}$ with the molar composition of the reacting oxides and heat-treatment temperature, and that these are correspond with their microstructure, while the Ms is precisely determined by the concentration of the reacting oxides in $\mathrm{Fe}_{2} \mathrm{O}_{3}$ up, heattreatment temperature demonstrated the breaking of the ferrimagnetic dendrites above $800^{\circ} \mathrm{C}$ correlates with the significant changes in the magnetic properties of the material, changes are related with a progressive conversion of magnetite into $\mathrm{Fe}_{2} \mathrm{O}_{3}$ [75].

In work reported by Bretcanu et al. [31] in 2006, ferrimagnetic $\mathrm{CaO}-\mathrm{SiO}_{2}-\mathrm{P}_{2} \mathrm{O}_{5}-\mathrm{Na}_{2} \mathrm{O}-\mathrm{FeO}-\mathrm{Fe}_{2} \mathrm{O}_{3}$ glassceramics were prepared by two synthesis methods (traditional melting of commercial reagents and melting of coprecipitated powders) and then, the influence of the synthesis method on the magnetic properties and heat generation were compared. In further work, the magnetic properties of ferrimagnetic glass-ceramics obtained by a traditional melting method was analyzed as a function of the melting temperature [76]. Results of this research revealed that microstructure and, consequently, the magnetic properties of the ferrimagnetic glass-ceramics depend on the melting temperature. For all these materials, the crystalline phases are mainly magnetite and hematite embedded in an amorphous matrix. Also, the samples obtained by the co-precipitation method contain a higher quantity of magnetite than their corresponding specimens obtained by melting of commercial reagents [76]. In their following paper, Bretcanu et al. [77] showed that the glassceramic obtained by co-precipitation method contained 45 wt.\% of magnetite. Room-temperature magnetic measurements performed using a vibrating sample magnetometer (VSM) showed the highest values of saturation magnetization for co-precipitation samples, which have higher quantities of crystalline magnetite. Similar results were achieved for coercivity. As a result of calorimetric behaviors, the ferrimagnetic glass-ceramics synthesized by the traditional melting method showed higher specific power losses due to the considerable contribution of the eddy currents. This specific power loss represents the thermal energy which will generate the heating of the tumor tissues [31].

Tiberto et al. [78] investigated the time evolution of magnetic remanence (after sudden removal of the magnetic field) and the electrical resistance of the composition 24.7 $\mathrm{SiO}_{2}-13.5 \mathrm{Na}_{2} \mathrm{O}-13.5 \mathrm{CaO}-3.3 \mathrm{P}_{2} \mathrm{O}_{5}-14 \mathrm{FeO}-31 \mathrm{Fe}_{2} \mathrm{O}_{3}$ (wt $\%$ ). This composition was melted in Pt crucible at two different temperatures: $1550^{\circ} \mathrm{C}$ and $1500^{\circ} \mathrm{C}$ for $15 \mathrm{~min}$. Two samples were poured in a preheated mold and heat-treated at $600^{\circ} \mathrm{C} / 14 \mathrm{~h}$. The main crystalline phases identified were magnetite, hematite and a sodium calcium silicate. In all cases, the remnant magnetization exhibited a nonsaturating, monotonic decrease of its magnitude as a function of time. These results were attributed to disordered magnetic states present at the interface between adjacent magnetite crystals.

Singh and Srinivasan [79] reported a systematic investigation of magnetic properties of $(45-\mathrm{x}) \mathrm{CaO}-34 \mathrm{SiO}_{2}$ $16 \mathrm{P}_{2} \mathrm{O}_{5}-4.5 \mathrm{MgO}-0.5 \mathrm{CaF}_{2}-\mathrm{xFe}_{2} \mathrm{O}_{3}$ (where $\mathrm{x}=5-20 \mathrm{wt} \%$ ) ferromagnetic bioglass-ceramics. From the structural analysis, hydroxyapatite, magnetite, and wollastonite were identified as major crystalline phases in all the glassceramic samples containing iron oxide. Besides, akermanite was detected in glass-ceramic samples with high iron oxide content. Presence of akermanite in these glassceramics increases the hardness of these glass-ceramics, and this gives them an advantage over $\mathrm{CaO}$ based magnetic bioactive glass-ceramics due to their higher load bearing capacity [79]. Magnetic properties and heat generation capability of the glass-ceramic samples under high and clinically amenable magnetic fields were evaluated. The results indicated that samples with higher iron oxide concentration are capable of generating more heat for the same magnetic field sweep. The in vitro bioactivity was also evaluated; it was shown that bioactivity increases when the iron content is increased. Thus, compositions with higher iron oxide content contain higher amounts of bone mineral phases as well as the magnetic phase [79]. 
In the research work of by Abdel-Hameed et al. in 2008 [80], two different ferrimagnetic glass-ceramics in the $\mathrm{CaO}-\mathrm{SiO}_{2}-\mathrm{B}_{2} \mathrm{O}_{3}-\mathrm{Fe}_{2} \mathrm{O}_{3}$ system with a high quantity ( $60 \%$ weight) of magnetite were prepared. One group of samples (called FW) was based on wollastonite, and the adition of $\mathrm{ZnO}$ prepared another group (called $\mathrm{FH}$ ) with the composition based on hardystonite $\left(\mathrm{Ca}_{2} \mathrm{ZnSi}_{2} \mathrm{O}_{7}\right)$. The work aimed to study the effect of chemical composition, the amount of crystallized magnetite and microstructure of the ferrimagnetic glass-ceramics on magnetic properties [80]. The structural investigation's results show the precipitation of nanometric magnetite crystals in a glassy matrix in the as-prepared samples (without heat treatment). The amount of magnetite precipitated in FH glass sample is higher than that precipitated in FW. It is seemed that the presence of $\mathrm{ZnO}$ in $\mathrm{FH}$, which leads to decrease of viscosity, leads to a higher degree of crystallinity [81] heat treatment at $800^{\circ} \mathrm{C} / 1 \mathrm{~h}$ revealed the crystallization of magnetite with a minor amount of hematite in the FW and significant magnetite with traces of hematite and wollastonite in the FH glass. Also, crystal size calculations showed precipitated magnetite crystallite size depending on the heat treatment parameters [81]. From the magnetic hysteresis, cycles analyze; they observed that all samples exhibit magnetic behavior characteristic for soft magnetic particles, with small coercivity.

Singh et al. [82] prepared glasses with composition 41CaO-(52-x) $\mathrm{SiO}_{2}-4 \mathrm{P}_{2} \mathrm{O}_{5}-\mathrm{xFe}_{2} \mathrm{O}_{3}-3 \mathrm{Na}_{2} \mathrm{O}(\mathrm{x}=0,2,4,6,8$ and $10 \mathrm{~mol} \%$ ) by melting-quenching technique. According to the authors, $\mathrm{Na}_{2} \mathrm{O}$ was added to increase solubility, and therefore, the apatite formation ability. After preparation, the samples were heat-treated at $1050^{\circ} \mathrm{C}$ for $3 \mathrm{~h}$, and three main crystalline phases were obtained: hydroxyapatite, wollastonite, and magnetite. The addition of $\mathrm{Fe}_{2} \mathrm{O}_{3}$ (from 2 to $10 \mathrm{~mol} \%$ ) caused four main effects: (1) the volume crystalized fraction of magnetite phase increased from $0.18 \mathrm{~nm}$ to $8.64 \mathrm{~nm}$; (2) the crystallite size increased from $32 \mathrm{~nm}$ to $56 \mathrm{~nm}$; (3) $\mathrm{M}_{S}$ increased from $0.17 \mathrm{emu} / \mathrm{g}$ to $7.95 \mathrm{emu} / \mathrm{g}$ and (4) $\mathrm{H}_{C}$ decreased from 523 Oe to 91 Oe.

In 2010, Martinelli et al. [83] were the first to develop glass-ceramic microspheres, although magnetite microspheres had been reported years before, Masakazu et al. [84]. Martinelli et al. [83] prepared an aluminiumiron-silicate glass $\left(\mathrm{Na}_{2} \mathrm{O}-\mathrm{CaO}-\mathrm{Al}_{2} \mathrm{O}_{3}-\mathrm{Fe}_{2} \mathrm{O}_{3}-\mathrm{SiO}_{2}\right.$ system) containing nucleating agents $\left(\mathrm{TiO}_{2}\right.$ and $\left.\mathrm{MnO}\right)$, melted at $1550^{\circ} \mathrm{C}$ for $2 \mathrm{~h}$ in an alumina crucible. The glass was crushed and sieved between 38 and $63 \mathrm{~m}$; the powder composed of particles of irregular shape (Figure 5-5a) was transformed into microspheres by using a process known as "spheronization by flame" (Figure 5-5b). When the microspheres were heat-treated at $650^{\circ} \mathrm{C}$ in an oxidizing at- mosphere, only magnetite and $\mathrm{SiO}_{2}$ were identified; however, in reducing atmosphere maghemite was also observed. In both cases, the crystallite size of magnetite varied from 10 to $16 \mathrm{~nm}$. It was found that a high $\mathrm{SiO}_{2}$ phase content produces a poor magnetization of the sample (only $1.2 \mathrm{emu} / \mathrm{g}$ at the saturation). After testing many compositions, the maximum $\mathrm{M}_{S}$ achieved was $15 \mathrm{emu} / \mathrm{g}$ (and an $\mathrm{H}_{C}$ of $\left.100 \mathrm{Oe}\right)$.
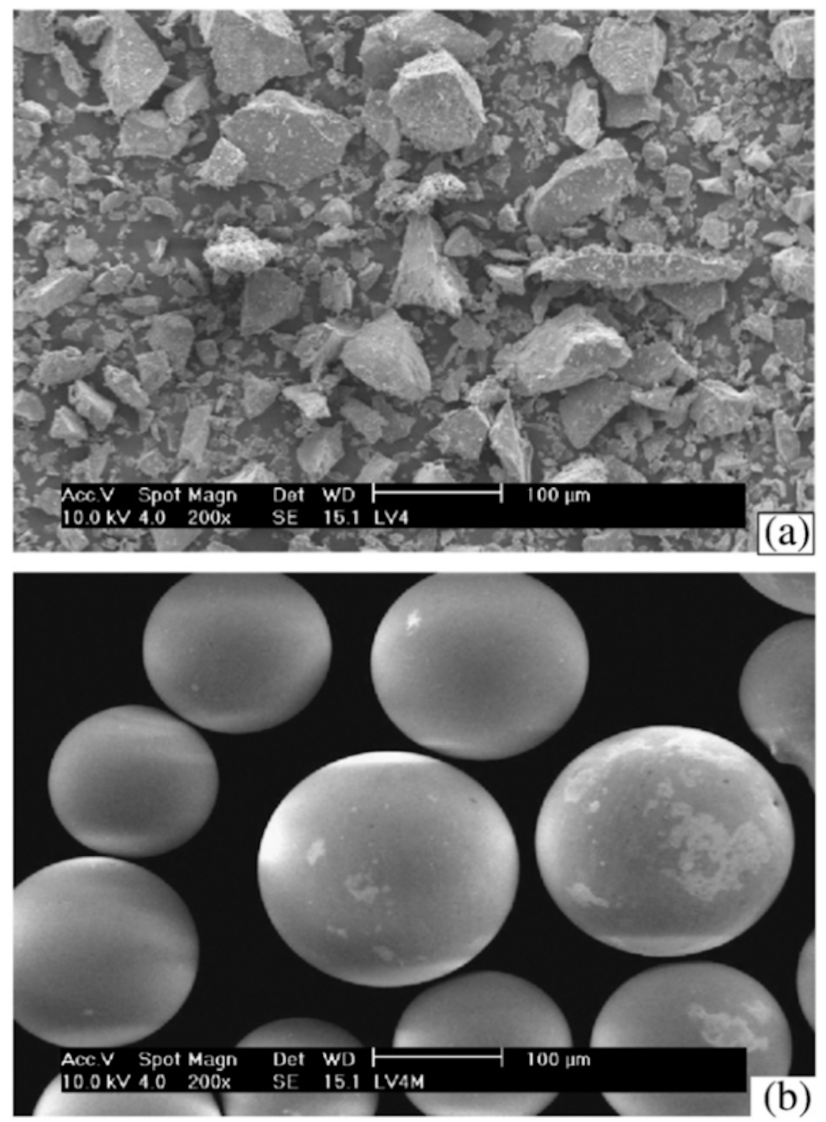

Figure 5: SEM micrographs of irregular glass particles (a) and the resulting microspheres (b) [83].

One year later, Zhang et al. [85] used the same technique to prepare glass-ceramic microspheres of composition $30 \mathrm{Fe}_{3} \mathrm{O}_{4}-30 \mathrm{SiO}_{2}-30 \mathrm{Y}_{2} \mathrm{O}_{3}-10 \mathrm{Al}_{2} \mathrm{O}_{3}$ (wt \%). However, in this case, the addition of $\mathrm{Y}_{2} \mathrm{O}_{3}$ was used as a strategy to create a glass-ceramic with a double functionality, i.e., both hyperthermia and radiotherapy. The authors obtained microspheres in the $20-30 \mu \mathrm{m}$ range. The XRD analysis showed that magnetic crystallite begins to form at around $700^{\circ} \mathrm{C}$ and the increasing of the heat-treatment temperature can improve the crystallization of $\mathrm{Fe}_{3} \mathrm{O}_{4}$. The maximum crystallite size of $17.6 \mathrm{~nm}$ was obtained for samples. Magnetic hysteresis loops showed that all the sam- 
ples exhibit soft magnetic behavior, with low coercivity. The $\mathrm{M}_{S}$ rose from $7.85 \mathrm{emu} / \mathrm{g}$ to $27.39 \mathrm{emu} / \mathrm{g}$ when the heattreatment temperature was increased from $700^{\circ} \mathrm{C}$ to $900^{\circ} \mathrm{C}$. The microspheres heat-treated at $900^{\circ} \mathrm{C}$ showed an outstanding combination of properties: a crystallite size of 17.6 $\mathrm{nm}$, the specific heat value of $7274.4 \mathrm{~J} / \mathrm{g}$, SAR value of 34.94 $\mathrm{W} / \mathrm{g}$ and a temperature increase of $17.3^{\circ} \mathrm{C}$ in $30 \mathrm{~min}$.

Using the sol-gel method, Vanea et al. [86] prepared glass-ceramics with composition $60 \mathrm{SiO}_{2}-20 \mathrm{Al}_{2} \mathrm{O}_{3}$ $10 \mathrm{Fe}_{2} \mathrm{O}_{3}-10 \mathrm{Dy}_{2} \mathrm{O}_{3} \quad(\mathrm{~mol} \%)$. Magnetite and hematite nanocrystallites developed after a heat treatment performed at $1200^{\circ} \mathrm{C}$; the presence of dysprosium originated a nearly superparamagnetic behavior, which is of interest for hyperthermia treatment.

Abdel-Hameed et al. [87] reported the preparation of five different glass-ceramics in the $\mathrm{Fe}_{2} \mathrm{O}_{3}-\mathrm{CaO}-\mathrm{SiO}_{2}$ system, containing small additions of $\mathrm{TiO}_{2}, \mathrm{Na}_{2} \mathrm{O}$, and $\mathrm{P}_{2} \mathrm{O}$ 5. The base composition was designed to crystallize about $60 \%$ magnetite. Heat treatment was carried out for the glasses in the temperature range of $1000-1050^{\circ} \mathrm{C}$, for different time periods, and led to the appearance of hematite and $\beta$-wollastonite, which was slightly increased by adding $\mathrm{P}_{2} \mathrm{O}_{5}$ or $\mathrm{TiO}_{2}$ and greatly enhanced by adding $\mathrm{Na}_{2} \mathrm{O}$. The microstructure of the samples was examined by using TEM, which revealed a crystallite size of magnetite to be in the range of 52-90 $\mathrm{nm}$. The maximum content of magnetite reached was $80 \%$ (wt \%); in this case, the MS was $59 \mathrm{emu} / \mathrm{g}$ for a maximum magnetic field of $10 \mathrm{kOe}$.

Liu et al. [88] investigated the systems $\mathrm{SrO}-\mathrm{Na}_{2} \mathrm{O}$ $\mathrm{Fe}_{2} \mathrm{O}_{3}-\mathrm{FeO}-\mathrm{P}_{2} \mathrm{O}_{5}-\mathrm{SiO}_{2}$ and $\mathrm{CaO}-\mathrm{Na}_{2} \mathrm{O}-\mathrm{Fe}_{2} \mathrm{O}_{3}-\mathrm{FeO}-\mathrm{B}_{2} \mathrm{O}_{3}-$ $\mathrm{SiO}_{2}$. The glasses were prepared by co-precipitation method followed by melting at $1480^{\circ} \mathrm{C}$ for $1 \mathrm{~h}$. These glasses contain single magnetite crystals, for all of the samples obtained by annealing and heat treatment, the magnetic performance of samples is not significantly improved. When a value of iron oxide content more than $40 \%$ (wt $\%$ ), the magnetic performance of samples is not significantly improved with the increase of iron oxide content [89].

Bioglass with a composition of $41 \mathrm{CaO}-44 \mathrm{SiO}_{2}-$ $4 \mathrm{P}_{2} \mathrm{O}_{5}-8 \mathrm{Fe}_{2} \mathrm{O}_{3}-3 \mathrm{Na}_{2} \mathrm{O}$ treated at different temperatures for $1 \mathrm{~h}, 2 \mathrm{~h}$, and $3 \mathrm{~h}$, denominated MBCs was development by Shankhwar et al. [90]. A systematic study of the evolution of structure and properties of these MBCs were carried out. Growth and crystallization of several bone mineral phases observed which confirm the biocompatible nature of the MBCs. Heat treatment up to $1050^{\circ} \mathrm{C}$ for $2 \mathrm{~h}$ improved the magnetic properties of the MBC. Deterioration of the features beyond $1050^{\circ} \mathrm{C}$ explained by the use of XRD magnetometry and EPR data. EPR studies show that for $\mathrm{T}_{A}$ $>1050^{\circ} \mathrm{C}$, precipitation of a non-magnetite phase takes place in the glassy matrix, this suppresses the super exchange interaction between the neighbors and results in the marked deterioration of the magnetic properties of the glass heat treated beyond $1050^{\circ} \mathrm{C}$. XRD studies lend support to the presence of $\alpha-\mathrm{Fe}_{2} \mathrm{O}_{3}$ phase in this MBC. Thus, the $41 \mathrm{CaO}-44 \mathrm{SiO}_{2}-4 \mathrm{P}_{2} \mathrm{O}_{5}-8 \mathrm{Fe}_{2} \mathrm{O}_{3}-3 \mathrm{Na}_{2} \mathrm{O}$ glass, which is Hench's composition [91] containing $\mathrm{Fe}_{2} \mathrm{O}_{3}$, is best suited for use as a thermoseed in hyperthermia treatment of cancer when heat-treated at $1050^{\circ} \mathrm{C}$ for $2 \mathrm{~h}$.

In the study of Abdel-Hameed et al. [92] of compact bodies of glass ceramics contain single domain particles $(<100 \mathrm{~nm})$ in the system $\mathrm{Fe}_{2} \mathrm{O}_{3}-\mathrm{TiO}_{2}-\mathrm{P}_{2} \mathrm{O}_{5}-\mathrm{SiO}_{2}-\mathrm{MO}(\mathrm{M}=$ $\mathrm{Mg}, \mathrm{Ca}, \mathrm{Mn}, \mathrm{Cu}, \mathrm{Zn}$ or $\mathrm{Ce}$ ) were prepared for cancer treatment by hyperthermia and localized delivery of an anticancer drug. Zn sample is found to be capable of generating more heat than the other samples. The significant variation in the area under the loops for studied samples provides a mean for controlling the generated temperature by the appropriate choice of sample. Results of this study reveal that the mechanism of drug release is diffusion-controlled mechanism and the rates of drug release from samples depend significantly on the concentration of loaded drug during the loading stage.

The glasses prepared by Sharma et al. [93] were found to be paramagnetic in nature. $\mathrm{Fe}^{3+}$ and $\mathrm{Fe}^{2+}$ ions in these glasses are present in octahedral and tetrahedral coordination, respectively. This glass containing $15 \mathrm{wt} . \% \mathrm{Fe}_{2} \mathrm{O}_{3}$, nearly $16 \%$ of the total iron entered as $\mathrm{Fe}^{3+}$ ions in tetrahedral coordination, entered in the glass network as a glass former. There was an increase in the saturation magnetization with increase in $\mathrm{Fe}_{2} \mathrm{O}_{3}$ content. The samples with iron concentration above $10 \mathrm{wt} . \%$ were ferrimagnetic. The glass-ceramic having $15 \mathrm{wt} . \% \mathrm{Fe}_{2} \mathrm{O}_{3}$ were biosorbable and bioactive, thus exhibiting the possibility of being used as implant for hyperthermia application.

Magnetite is proven to be non-toxic and biocompatible. The iron oxide is determined to be nontoxic and biocompatible. Such properties are important because they ensure that the patient is comfortable during the therapy. Furthermore, the iron oxide nanoparticles work great with the magnetic force to heat the target area in cancer therapy. The nanoparticles are given a special coating particularly the aminosilane before the particles are transmitted to the tumor. The ling ensures that the nanoparticles move target tissue rather than spreading out to other parts of the body to cause additional complications during the hyperthermia [94]. 


\subsection{Zinc ferrite glass-ceramics}

Kawashita et al. prepared in 2004 [81], a glassceramic powder containing zinc-iron ferrite $\left(\mathrm{Zn}_{x} \mathrm{Fe}_{3-x} \mathrm{O}_{4}\right)$ in a $\mathrm{CaO}-\mathrm{SiO}_{2}$ glassy matrix by heat treatment of $43 \mathrm{CaO} \cdot 43 \mathrm{SiO}_{2} \cdot 14 \mathrm{Zn}_{0.4} \mathrm{Fe}_{2.6} \mathrm{O}_{4}(\mathrm{~mol} \%)$ glasses in a controlled atmosphere. The effects of various temperature and heat treatments on the structure and magnetic properties of the material were investigated. The results revealed that $\mathrm{Zn}_{x} \mathrm{Fe}_{3-x} \mathrm{O}_{4}$ crystals precipitated above $700^{\circ} \mathrm{C}$, and their content and size increased with increasing heat treatment temperature up to $1150^{\circ} \mathrm{C}$. The saturation magnetization of the heat treated powders increased with increasing heat treatment temperature up to $1150^{\circ} \mathrm{C}$. But the coercive force of the specimen increased only up to $1000^{\circ} \mathrm{C}$, then decreased with increasing treatment temperature. When the heat treatment time at $1150^{\circ} \mathrm{C}$ was increased from $1 \mathrm{~h}$ to $5 \mathrm{~h}$, the content of the $\mathrm{Zn}_{x} \mathrm{Fe}_{3-x} \mathrm{O}_{4}$ was not changed, whereas the crystallite size of the $\mathrm{Zn}_{x} \mathrm{Fe}_{3-x} \mathrm{O}_{4}$ increased. The coercive field of the heat-treated powders increased, and the saturation magnetization of the specimen decreased since the fraction of paramagnetic iron ions was increased by the heat treatment for five h. Additionally, the powders heat treated at $1150^{\circ} \mathrm{C}$ for five hours showed maximum heat generation, $12.4 \mathrm{~W} \cdot \mathrm{g}^{-1}$, which is larger than that all the previous glass ceramics containing magnetite $(<10$ $\left.\mathrm{W} \cdot \mathrm{g}^{-1}\right)$. In conclusion, this glass-ceramic may be a promising candidate for thermoseeds in for HT due to a high heat generating ability [81].

Shah et al. and Saqlain et al. in 2010 [95-97], reported on a different ferrimagnetic zinc-ferrite $\left(\mathrm{ZnFe}_{2} \mathrm{O}_{4}\right)$ containing bioglass for cancer treatment. For this purpose, glass-ceramics of the composition $25 \mathrm{CaO}-(40-\mathrm{x}) \mathrm{SiO}_{2}$ $7 \mathrm{P}_{2} \mathrm{O}_{5}-3 \mathrm{Na}_{2} \mathrm{O}-\mathrm{xZnO}-25 \mathrm{Fe}_{2} \mathrm{O}_{3}(\mathrm{x}=4,6,8,10)$ were prepared by quenching the glass-powders from sintering temperature [95]. Structural studies of the material done with Xray diffraction (XRD) revealed three prominent crystalline phases: zinc ferrite, wollastonite and hydroxyapatite [95]. Generally, $\mathrm{ZnFe}_{2} \mathrm{O}_{4}$ is paramagnetic due to its normal spinel structure, but in this work, $\mathrm{ZnFe}_{2} \mathrm{O}_{4}$ exhibited ferrimagnetism due to the random distribution of $\mathrm{Zn}^{2+}$ and $\mathrm{Fe}^{3+}$ cations at tetrahedral A sites and octahedral B sites and thus the strong exchange $\mathrm{A}-\mathrm{B}$ interactions. The inversion/random distribution of cations was probably due to the surface effects of nano-structure of $\mathrm{ZnFe}_{2} \mathrm{O}_{4}$ and rapid cooling of the material from $1100^{\circ} \mathrm{C}$ (thus preserving the high-temperature state of the random distribution of cations) [95]. Magnetic evaluations of these ferrimagnetic glass-ceramics by VSM data at $10 \mathrm{kOe}$ and 500 Oe showed that saturation magnetization, coercivity and hence hysteresis area increased with the increase in $\mathrm{ZnO}$ content due to magnetic $\mathrm{ZnFe}_{2} \mathrm{O}_{4}$ phase [95]. As well as, since the nanosized $\mathrm{ZnFe}_{2} \mathrm{O}_{4}$ crystallites were of pseudo-single domain structure, thus coercivity increased with the increase of the crystallite size. Figure 2 shows the crystallite size of zinc-ferrite as a function of $\mathrm{ZnO}$ content and its impact on coercivity [95]. Calorimetric measurements carried out using magnetic induction furnace at 500 Oe magnetic field and $400 \mathrm{kHz}$ frequency showed that maximum specific power loss and temperature increase after $2 \mathrm{~min}$ were 26 $\mathrm{W} / \mathrm{g}$ and $37^{\circ} \mathrm{C}$, respectively for the sample containing $10 \%$ of $\mathrm{ZnO}$ (maximum zinc-ferrite content) [95].

A study conducted by Singh and Srinivasan in 2010 [98, 99], reports on ferromagnetic $(65-\mathrm{x}) \mathrm{SiO}_{2}$ $20\left(\mathrm{CaO}, \mathrm{P}_{2} \mathrm{O}_{5}\right)-15 \mathrm{Na}_{2} \mathrm{O}-\mathrm{x}\left(\mathrm{ZnO}, \mathrm{Fe}_{2} \mathrm{O}_{3}\right)(6 \leq \mathrm{x} \leq 21 \mathrm{~mol} \%)$ bioactive glass-ceramics for cancer hyperthermia. From structural studies, they found that sodium calcium phosphate $\left(\mathrm{NaCaPO}_{4}\right)$ and zinc ferrite $\left(\mathrm{ZnFe}_{2} \mathrm{O}_{4}\right)$ are the major crystalline phases formed [65-66]. Magnetic properties of these glass-ceramics originate from the nano-crystalline zinc-ferrite present [101]. Evolution of magnetism in this series of glass-ceramics, from a partially paramagnetic to fully ferrimagnetic material as a function of zinc-iron oxide content is observed [100,101]. Initial magnetization curves of the glass-ceramics containing zinc ferrite (Figure 1) reveal that the samples with zinc-iron oxide content up to $9 \mathrm{~mol} \%$ exhibit both ferrimagnetic and paramagnetic contributions, whereas, the samples with $x \geq 9$ mol\% zinc-iron oxide exhibit only ferrimagnetic contribution. As can be seen in Figure 1, the magnetization curves of the samples with $\mathrm{x}=6$ and 9 do not saturate under an applied magnetic field, while the magnetization curves of samples with $\mathrm{x}=12,15,18$ and $21 \mathrm{~mol} \%$ zinc-iron oxide are saturated [100]. Also, maximum magnetic hysteresis loss inducing heat generation was obtained in glass-ceramics samples with a higher zinc ferrite content [101].

Shah et al. [102] enhanced the magnetic and heat generating properties of the ferrimagnetic zinc-ferrite containing bioglass via an aligned magnetic field. To introduce magnetic anisotropy, after preparation of a ferrimagnetic bioactive glass-ceramic in the above system $(\mathrm{CaO}-$ $\mathrm{SiO}_{2}-\mathrm{P}_{2} \mathrm{O}_{5}-\mathrm{Na}_{2} \mathrm{O}-\mathrm{ZnO}-\mathrm{Fe}_{2} \mathrm{O}_{3}$ ), the samples were heated to $600^{\circ} \mathrm{C}$ and cooled in an aligning magnetic field of 10 kOe. Next, the magnetically aligned samples were compared with nonaligned samples [97, 103]. VSM measurements taken at $10 \mathrm{kOe}$ and 500 Oe (Figure 3) showed that the coercive field, remnant magnetization and hysteresis area increased for the aligned samples. After cooling, the domains were trapped and became stable along the direction of aligning field. A stronger magnetic field was required to turn the domains away from their aligned positions. Thus, magnetic properties were enhanced by the 
aligning magnetic field, and it leads to an increase of the heat generation under magnetic induction furnace [97, 103]. The magnetic parameters variations become more prominent for $\mathrm{x}=8-12$ due to a greater content of ferrimagnetic zinc-ferrite phases [97, 103]. The data of the calorimetric studies carried out using magnetic induction furnace at $500 \mathrm{Oe}$ and $60 \mathrm{kHz}$ frequency showed that maximum specific power loss and temperature increase after $2 \mathrm{~min}$ were $4.4 \mathrm{~W} / \mathrm{g}$ and $6.3^{\circ} \mathrm{C}$ respectively for the aligned sample of maximum zinc-ferrite crystalline content [97]. Even these values were reached to $31.5 \mathrm{~W} / \mathrm{g}$ and $45^{\circ} \mathrm{C}$ in a furnace operating at $500 \mathrm{Oe}$ and $400 \mathrm{kHz}$ for $2 \mathrm{~min}$ [103]. The variation of specific power loss is more prominent for $\mathrm{x}=8$ and $\mathrm{x}=10$, fallowing the variations in hysteresis areas [103]. The importance of these works lies in the fact that the calorimetric properties and magnetic heating capabilities of the zincferrite-containing ferrimagnetic bioactive glass ceramics have been enhanced simply by cooling the materials in an aligning magnetic field, without any compositional or microstructural changes in the glass-ceramics [97, 103].

In the work of Shankhwar et al. [104] observed in all heat-treated samples, the growing of bone mineral phase primarily responsible for the bioactive nature of the glass-ceramics. Jiang et al. [105] Obtain submicron particles ranged from 128 to $525 \mathrm{~nm}$, and these particles could be located near a tumor to provide treatment, thus, particles could be delivered into tumor cells via endocytosis, the temperature that this material might produce is $50^{\circ} \mathrm{C}$ around the tumor, and the biological activity and osteoblast induction of the material achieved the expected target.

\subsection{Strontium ferrite glass-ceramics}

The research work of Intawin et al. [106] showed the influence of the sintering temperature on the properties of SF- $\mathrm{P}_{2} \mathrm{O}_{5}-\mathrm{CaO}-\mathrm{Na}_{2} \mathrm{O}$ bioactive glass-ceramics prepared by a sintering method. After sintering, the Vickers hardness was correlated with density, pores, and crystal and liquid phases present in the material. These bioactive glassceramics contain $\mathrm{SrFe}_{12} \mathrm{O}_{19}$ and $\mathrm{Ca}_{2} \mathrm{P}_{2} \mathrm{O}_{7}$. the XRD patterns show that $\mathrm{SrFe} 12 \mathrm{O} 19$ crystallite size decreases as the sintering temperature increases. EDS and SEM results confirmed the growth of hydroxyapatite after immersion in SBF for seven days, suggesting that these materials are bioactive and could bond to living tissues in the physiological environment. VSM data showed that the coercivity increased with increasing sintering temperature. Furthermore, the maximum SrFe12O19 crystallite size and high- est crystallinity were observed for the material sintered at $500^{\circ} \mathrm{C}$, which also have the highest Ms and Mr values.

In 2013, Leenakul et al. [107] reported a bioactive glassceramic containing strontium ferrite $(\mathrm{SrF})$ as the magnetic phase for the first time [108]. It is already known that strontium-doped bioactive silicate glass discs enhance bone cell activity and promote osteoblast proliferation and alkaline phosphatase activity when directly applied in contact with cells. Therefore, Leenakul et al. fabricated $\mathrm{SiO}_{2}-\mathrm{CaO}-\mathrm{Na}_{2} \mathrm{O}-\mathrm{P}_{2} \mathrm{O}_{5}$ bioactive glass-ceramics containing $\mathrm{SrFe}_{12} \mathrm{O}_{19}(\mathrm{SrFe})$ by using a solid-state sintering method. In this method, SrF crystals were first produced using solid-state sintering technique and then added to 45S5 bioglass powder, which was then further mixed and sintered to form the glass-ceramic [107]. The influence of SrF addition on the microstructure of the prepared glassceramics was studied, and results showed that upon heat treatment, sodium calcium silicate $\left(\mathrm{Na}_{4} \mathrm{Ca}_{4} \mathrm{Si}_{6} \mathrm{O}_{18}\right)$, strontium iron oxide $\left(\mathrm{SrFe}_{12} \mathrm{O}_{19}\right)$, and iron oxide $\left(\mathrm{Fe}_{2} \mathrm{O}_{3}\right)$ crystallized in all samples [108]. Considering the hysteresis loops, these ferrimagnetic glass-ceramics showed a wide hysteresis loop and high coercive field, which confirms their character of hard magnetic materials. Also, their magnetic properties were strongly dependent on the addition of $\mathrm{SrF}$. The saturation magnetization, remanence, and coercivity grew with $\mathrm{SrF}$ content.

Abbasi et al. [109] doped strontium hexaferrite $\left(\mathrm{SrFe}_{12} \mathrm{O}_{19}\right)$ to $45 \mathrm{~S} 5$ bioglass and prepared ferrimagnetic bioactive glass-ceramics through a different, economical technique. They synthesized the bioactive material by the solid-state reaction method rather than the conventional melt-quenching one using soda- lime-silica waste glass as the primary raw material. Then sol-gelprepared $\mathrm{SrFe}_{12} \mathrm{O}_{19}$ nanoparticles were added to the bioactive matrix phase in different amounts, 5-20 wt.\%. Finally, the resulting ferrimagnetic bioactive glass-ceramic samples were prepared by sintering the mixed powder [110]. After sintering, three main phases were identified: $\mathrm{Na}_{2} \mathrm{Ca}_{2} \mathrm{Si}_{3} \mathrm{O}_{9}, \mathrm{NaCaPO}_{4}$ and $\mathrm{SrFe}_{12} \mathrm{O}_{19}$. The size of $\mathrm{SrFe}_{12} \mathrm{O}_{19}$ crystalswas proportional to the content of strontium hexaferrite in the samples and increased with the amount of magnetic phase [110]. Under a magnetic field up to saturation, as expected, saturation magnetization and remanence magnetization values increase by increasing the amount of $\mathrm{SrFe}_{12} \mathrm{O}_{19}$ phase since these parameters depend on the concentration of the magnetic phase. On the other hand, the coercive force values increase by expanding the hexaferrite content due to the dependence of coercivity on the crystallite size. Moreover, the energy loss or the heat generated by a ferrimagnetic ceramic increase by increasing the amount of the mag- 
netic phase and reach to $75.852 \times 10^{3} \mathrm{erg} / \mathrm{g}$ for the sample containing $20 \mathrm{wt} \% \mathrm{SrFe}_{12} \mathrm{O}_{19}$, which is appropriate for hyperthermia therapy [110]. In this study, the in vitro test was utilized to assess the bioactivity level of the samples, by Hanks solution and showed that the onset time of the hydroxycarbonate apatite layer formation on undoped glass-ceramics was 7 days, while at least 14 days are required for an apatite layer to be formed on the surface of the glass-ceramic doped with strontium hexaferrite. Here, Abbasi et al. deduced that doping of strontium ferrite to Bioglasss4 5S5 glass was likely to decrease bioactivity because the amount of non-bioactive phase (magnetic phase) increased by the addition of strontium ferrite [110].

\subsection{Barium ferrites}

Intawin et al. [111] reported a bioactive glass ceramics with barium ferrite content (BF) varied from 5 - $40 \mathrm{wt} . \%$ were fabricated. The $\left(\mathrm{BaFe}_{12} \mathrm{O}_{19}\right),\left(\mathrm{Na}_{1.8} \mathrm{Ca}_{1.1} \mathrm{P}_{6} \mathrm{O}_{17}\right)$, $\left(\mathrm{CaH}_{2} \mathrm{P}_{2} \mathrm{O}_{7}\right),\left(\mathrm{Ca}_{2} \mathrm{P}_{2} \mathrm{O}_{7}\right)$ and $\left(\mathrm{NaFe}\left(\mathrm{P}_{2} \mathrm{O}_{7}\right)\right)$ phases were detected in the XRD patterns, magnetometer (VSM) data at $8 \mathrm{kOe}$ showed that remnant magnetization and coercivity and hence hysteresis area increased with the increase in BF content. In vitro tests were conducted on the glass ceramics samples by examining their apatite-forming ability in SBF. SEM studies revealed an increase in apatiteforming ability with an increase in BF content in the prepared glass-ceramics. A similar result with the bioactivity in the glass-ceramic sample containing BF was reported in the work of Leenakul et al. [112] was seen that there was a remarkable increase in $\mathrm{Ba}$ together with $\mathrm{Ca}$ and $\mathrm{P}$ content, while $\mathrm{Si}$ content decreased with increasing $\mathrm{BF}$ content and sintering temperature. The $\mathrm{BF}$ content and sintering temperature also influenced the bioactive behavior of samples. In this sense, it was observed that the layer formation rate for this glass-ceramics was higher in samples containing $\mathrm{Ba}$ and sintering at high temperature especially at $850^{\circ} \mathrm{C}$ exhibited better apatite cell growth.

\subsection{Other ferrites}

It has been shown that bioactive glasses and glassceramics bond to bone by the formation of an apatite layer on the surface [91], a possibility explored in the study of Jagadish et al. [113] through the synthesis a Ca-ferrite based biocompatible glass-ceramic. Their results have shown that glass ceramics from two different systems $\left(28 \mathrm{Na}_{2} \mathrm{O}-8 \mathrm{CaO}-\right.$ $3 \mathrm{P}_{2} \mathrm{O}_{5}-11 \mathrm{Fe}_{2} \mathrm{O}_{3}-50 \mathrm{SiO}_{2}$ and $25 \mathrm{Na}_{2} \mathrm{O}-8 \mathrm{CaO}-3 \mathrm{P}_{2} \mathrm{O}_{5}-20 \mathrm{Fe}_{2} \mathrm{O}_{3}-$ $41 \mathrm{SiO}_{2}-3 \mathrm{~B}_{2} \mathrm{O}_{3}$ in \%wt.) had their apatite layer formation delayed by the presence of $\mathrm{Al}^{3+}$, but ferromagnetic resonance experiments at 9-03 GHz demonstrated that these glass-ceramics could possibly be applied for microwave hyperthermia.

The use of magnesium ferrite was studied by Da Li et al. [114] development novel magnetic bioactive glass-ceramic in the system $\mathrm{CaO}-\mathrm{SiO}_{2}-\mathrm{P}_{2} \mathrm{O}_{5}-\mathrm{MgO}-$ $\mathrm{CaF}_{2}-\mathrm{Fe}_{2} \mathrm{O}_{3}$ was synthesized by doping $\mathrm{Mg}$ ferrite to wollastonite-fluorapatite containing glass-ceramics. $\mathrm{CaSiO}_{3}, \mathrm{Ca}_{2}, \mathrm{Mg}, \mathrm{Si}_{2} \mathrm{O}_{7}, \mathrm{Ca}_{5}\left(\mathrm{PO}_{4}\right)_{3} \mathrm{~F}$ and $\mathrm{Fe}_{2} \mathrm{MgO}_{4}$ were the main phases of the novel material. The doping of $\mathrm{Mg}$ ferrite obtained a magnetic behavior to the glass-ceramic. Under a magnetic field of $10 \mathrm{kOe}$, the saturation magnetization and coercive field of the sample were $7.2 \mathrm{emu} / \mathrm{g}$ and 175 Oe, respectively. Though doping of Mg ferrite decreased the bioactivity of the material, a lot of hydroxyapatite containing $\mathrm{CO}_{3}^{2-}$ were observed on the surface of the sample after soaking in SBF for 14 days. The experiment of co-culturing ROS 17/2.8 cells with the glass-ceramic showed that the cells could attach well to the material. The material has the potential to be used as thermoseeds for hyperthermia.

Li et al. [115] doped $\mathrm{Mn}-\mathrm{Zn}$ ferrite as the magnetic phase in an apatite-wollastonite glass-ceramic, and synthesized a novel magnetic bioactive glass-ceramic in the system $\mathrm{CaO}-\mathrm{SiO}_{2}-\mathrm{P}_{2} \mathrm{O}_{5}-\mathrm{MgO}-\mathrm{CaF}_{2}-\mathrm{MnO}-\mathrm{ZnO}-$ $\mathrm{Fe}_{2} \mathrm{O}_{3}$ by the sol-gel method. Then, they investigated the effect of different contents of $\mathrm{Mn}-\mathrm{Zn}$ ferrite on the phase structure, magnetic property and bioactivity of these glassceramics [115]. Apatite-wollastonite glass-ceramics exhibited apatite, fluorapatite, and wollastonite as the main phases, whereas doping of $\mathrm{Mn}-\mathrm{Zn}$ ferrite caused the formation of a new phase $\mathrm{Zn}_{0.75} \mathrm{Mn}_{0.75} \mathrm{Fe}_{1.5} \mathrm{O}_{4}$. Under a magnetic field, the saturation magnetization of the glassceramics increased, while their coercive fields decreased as the $\mathrm{Mn}-\mathrm{Zn}$ ferrite content increased from 5\% to $20 \%$ in the material. The bioactivity results of this research showed that the doping of $\mathrm{Mn}-\mathrm{Zn}$ ferrite decreased the bioactivity of the glass-ceramics dramatically. Indeed, it took seven days for an apatite layer to form on the surface of apatite-wollastonite glass-ceramic, while at least 30 days was needed for an apatite layer to develop on the surface of the glass-ceramic doped with Mn-Zn ferrite [115].

The magnetic glass-ceramics prepared for Abe et al. [116] by quenching an immiscible phase-separated melt of the $\mathrm{Fe}_{3} \mathrm{O}_{4}-\mathrm{MnO}_{2}-\mathrm{SiO}_{2}$ system, resulted in the formation of the multiple magnetic domain structure. These results show that the Mn doping in this system is very useful to realize the magnetic materials having both a high magnetization and a low coercive field and that the obtained material will be possible to suppress the burden of patients in the 
hyperthermia treatment because of using a lower applied magnetic field. They did not report any studies of bioactivity or tests in vitro with SBF.

Hsi et al. [117] prepared glasses consisting of 25 at. $\% \mathrm{Li}_{2} \mathrm{O}, 8$ at. $\% \mathrm{MnO}_{2}, 20$ at. $\% \mathrm{CaO}, 2$ at. $\% \mathrm{P}_{2} \mathrm{O}_{5}$ and 45 at. $\% \mathrm{SiO}_{2}$ doped with 0,4 , and 8 at. $\%$ of $\mathrm{Fe}_{2} \mathrm{O}_{3}$. These researchers studied the crystallization behavior and magnetic properties of this system [117]. These glasses showed predominant surface nucleation after various heat-treatment processes. When heat-treated at $850^{\circ} \mathrm{C}$ for $4 \mathrm{~h}, \mathrm{LiMn}_{2} \mathrm{O}_{4}, \beta$-wollastonite $\left(\beta\right.$ - $\left.\mathrm{CaSiO}_{3}\right)$, lithium silicate ( $\left.\mathrm{Li}_{2} \mathrm{SiO}_{3}\right), \mathrm{Ca}(\mathrm{Ca}, \mathrm{Mn}) \mathrm{Si}_{2} \mathrm{O}_{6}$ and $\mathrm{Li}_{2} \mathrm{Ca}_{4} \mathrm{Si}_{4} \mathrm{O}_{13}$ phases were found in $20 \mathrm{CaO}-45 \mathrm{SiO}_{2}-2 \mathrm{P}_{2} \mathrm{O}_{5}-25 \mathrm{Li}_{2} \mathrm{O}-8 \mathrm{MnO}_{2}$ (without $\left.\mathrm{Fe}_{2} \mathrm{O}_{3}\right)$ glasses. Whereas the ( $\left.\mathrm{Li}, \mathrm{Mn}\right)$ ferrite phase was obtained in all the iron oxide contained compositions, whereas the $\mathrm{Li}_{2} \mathrm{FeMn}_{3} \mathrm{O}_{8}$ phase was found in that containing 8 at. $\% \mathrm{Fe}_{2} \mathrm{O}_{3}$ [117]. TEM investigations showed the presence of $(\mathrm{Li}, \mathrm{Mn})$ ferrite particles dispersed in a $\beta$ wollastonite matrix. These results also revealed that by varying the weight percentage of $\mathrm{Fe}_{2} \mathrm{O}_{3}$ in the composition, the ( $\mathrm{Li}, \mathrm{Mn})$ ferrite grain size could be controlled. The $(\mathrm{Li}, \mathrm{Mn}$ ) ferrite particle average size in the glass-ceramics containing 4 at. $\% \mathrm{Fe}_{2} \mathrm{O}_{3}$ was found to be $40 \mathrm{~nm}$ [117]. As the ( $\mathrm{Li}, \mathrm{Mn})$ ferrite grain size in the matrix glass became smaller than $40 \mathrm{~nm}$, the magnetic behavior showed mixed superparamagnetism and ferromagnetism in a rather complicated way. However, as the grain size grew larger, the magnetic behavior changed to ferromagnetism [117]. Confirming the mentioned findings, magnetometry SQUID results showed that only the glass-ceramic containing 4 at. $\%$ $\mathrm{Fe}_{2} \mathrm{O}_{3}$ exhibited superparamagnetic behavior at room temperature $(300 \mathrm{~K})$ and ferromagnetic behavior at $4 \mathrm{~K}$. While the glass-ceramic containing 8 at. $\% \mathrm{Fe}_{2} \mathrm{O}_{3}$ showed ferromagnetic behavior at both temperatures [117].

Da Li et al. [114] synthesized and characterized magnetic bioactive glass-ceramics in the system $\mathrm{CaO}-\mathrm{SiO}_{2}$ $\mathrm{P}_{2} \mathrm{O}_{5}-\mathrm{MgO}-\mathrm{CaF}_{2}-\mathrm{Fe}_{2} \mathrm{O}_{3}$ with $\mathrm{Mg}$ ferrite as the magnetic phase. The phase structure studies showed that wollastonite, akermanite $\left(\mathrm{Ca}_{2} \mathrm{MgSi}_{2} \mathrm{O}_{7}\right)$ and fluorapatite $\left(\mathrm{Ca}_{5}\right.$ $\left.\left(\mathrm{PO}_{4}\right)_{3} \mathrm{~F}\right)$ are the main phases of this bio glass-ceramic. Moreover, a new phase, $\mathrm{Fe}_{2} \mathrm{MgO}_{4}$, was detected due to the doping of $\mathrm{Mg}$ ferrite. According to magnetic measurements, these materials exhibit characteristics of soft magnetic materials, with a narrow hysteresis cycle and a small coercive field From the in vitro bioactivity assessment, though the doping of $\mathrm{Mg}$ ferrite decreased the bioactivity of the glass, but a significant amount of hydroxyapatite containing $\mathrm{CO}_{3}^{2-}$ were observed on the surface of the material after soaking in $\mathrm{SBF}$ for 14 days.

Bioactive glasses and glass-ceramics have demonstrated to be capable to bond to the host hard tissue and enhance new bone formation [48, 49, 57?]. Glass-ceramics began to appear in medicine in 1980, aiming to replace the previously used glasses in applications that demanded higher mechanical strength [118]. Glass-ceramics have advantages compared to other materials such as metal alloys, polymers or sintered ceramics [32], such as fast large scale, easy preparation, lack of porosity, easier microstructural control and the economic considerations. In addition, the glass-ceramic route is also very convenient for providing controllable particle size and morphology, as well as for obtaining narrow size distribution of nanoparticles and achieving good biocompatibility [24, 29].

Doping bioactive glasses and glass-ceramics with iron has been considered useful for cancer treatment materials because of its magnetic properties [113]. A large number of bioactive/biocompatible glass-ceramics have been exploited for such investigations [32, 74-76, 80, 81, 93, 98, $102,113,114,120-127]$. However, the increasing of $\mathrm{Fe}_{2} \mathrm{O}_{3}$ content in glass decreases the rate of apatite formation in vitro tests with Simulated Body Fluid (SBF) solution and suppresses the dissolution of calcium, thus inhibiting the formation of the silica gel layer [93]. Therefore, it takes a longer time to precipitate the calcium phosphate amorphous layer from the supersaturated solution. Hence, the rate of apatite formation (bioactivity) is reduced as observed in the samples [93, 128].

Magnetic glass-ceramics are expected to be useful in the treatment and elimination of cancer cells by HT. Through an alternating magnetic field, they can generate heat due to hysteresis loss. The manufacture of glassceramics is cost-effective and straightforward, being a more comfortable processing material than other magnetic nanoparticles obtained by sol-gel [27], such as silicabased magnetic nanoparticles [129] and granular films of $\mathrm{Fe}_{2} \mathrm{O}_{3}$ nanoparticles in an amorphous alumina matrix, obtained by co-sputtering [130]. Their processing route allows one to control the particle size and morphology which are the necessary specifications for biomaterial for HT applications [119].

The inclusion of magnetic aggregates in glasses or glass-ceramics could be a solution for the application of these materials in HT. With these composites, it is possible to achieve a chemical bond between the bioactive glass and the bone tissue, and concomitantly, it is possible to control the increase of the temperature due to the hysteresis loop of the magnetic material and the induced eddy currents when a variable external magnetic field is applied [120]. Thus, ferromagnetic bioactive glass-ceramics can be used, not only for the HT treatment of cancer but also as a substitute for a cancerous/damaged bone [131]. 
Most magnetic glass-ceramics contain $\mathrm{Fe}_{2} \mathrm{O}_{3}$ in their compositions, ranging from a few percent to $40 \%$ wt [54, $66,68-77]$. The most common glass-ceramic compositions for these purposes belong to the $\mathrm{SiO}_{2}-\mathrm{CaO}-\mathrm{P}_{2} \mathrm{O}_{5}-\mathrm{Na}_{2} \mathrm{O}$ $\mathrm{Fe}_{2} \mathrm{O}_{3}$ system. As mentioned, $\mathrm{Fe}_{2} \mathrm{O}_{3}$ addition to a bioactive glass-ceramic materials increases their chemical durability and, depending on the quantity that has been added to the glass. It can even suppress the HCA layer formation [137], so the bioactivity kinetics is slightly slower than of the top bioactive glasses [133]. This observed absence of in vitro bioactivity is attributed to small amounts of iron ions remaining in the glass matrix [138]. iron addition to the glass decrease $\mathrm{Ca}^{2+}$ release due to the formation of $\mathrm{Fe}-$ $\mathrm{O}-\mathrm{P}$ bonds, which are more resistant to hydration than the $\mathrm{P}-\mathrm{O}-\mathrm{P}$ bonds.

A previous study has shown that $\mathrm{Fe}_{2} \mathrm{O}_{3}$ containing $\mathrm{CaO}-\mathrm{SiO}_{2}$ glasses can present a certain level of bioactivity if small amounts of $\mathrm{Na}_{2} \mathrm{O}, \mathrm{B}_{2} \mathrm{O}_{3}$ or $\mathrm{P}_{2} \mathrm{O}_{5}$ are added [71]. This indicates that the ferrimagnetic glass-ceramic containing magnetite could perhaps show bioactivity if small amounts of these components are added to the composition in the parent glass [72]. Not only the addition of Fe can affect the bioactivity, but also the manufacturing route poses a high influence on the magnetic and biological properties of the glass-ceramic. The sol-gel route offers the advantage of a more rapid apatite-like layer growth, as a consequence of better textural properties [139].

Other processing parameters can also affect the magnetic properties of the biomaterial, such as the temperature in which the material is crystallized. Leventouri et al. [75] in the system $0.45\left(\mathrm{CaO}, \mathrm{P}_{2} \mathrm{O}_{5}\right)-(0.52-\mathrm{x}) \mathrm{SiO}_{2}-\mathrm{xFe}_{2} \mathrm{O}_{3}$ $0.03 \mathrm{Na}_{2} \mathrm{O}$ (\%mole), where $\mathrm{x}=0,0.05 ; 0.10,0.15,0.20$ is the molar concentrations in $\mathrm{Fe}_{2} \mathrm{O}_{3}$, that the loop area and magnetization decrease to a lower value depending on the heat-treatment, at elevated temperatures on the magnetic properties of the biomaterial is illustrated in Figure 6.

Another important parameter that is affected by the addition of iron to glass-ceramics is that the glass transition temperature increases. Problems with high temperatures are that in the crystallization of magnetite from glasses, the polyvalence of iron, which always occurs in glasses and melts, the $\mathrm{Fe}^{2+}$ and $\mathrm{Fe}^{3+}$ ratio and the magnetite crystal are easily oxidized or reduced [119]. Supersaturation of $\mathrm{Fe}^{3+}$ and $\mathrm{O}^{2-}$ at the surface results in the growth of a thin layer of hematite [32]. These ionic species are in equilibrium with the physically dissolved oxygen in the melt. In principle, the $\mathrm{Fe}^{2+} / \mathrm{Fe}^{3+}$ redox ratio can be adjusted by appropriate reducing or oxidizing conditions [119]. To solve this problem, Han Oh et al. [32] used carbon powder as an oxygen barrier during the heattreatment process. Carbon reacts very readily with oxygen

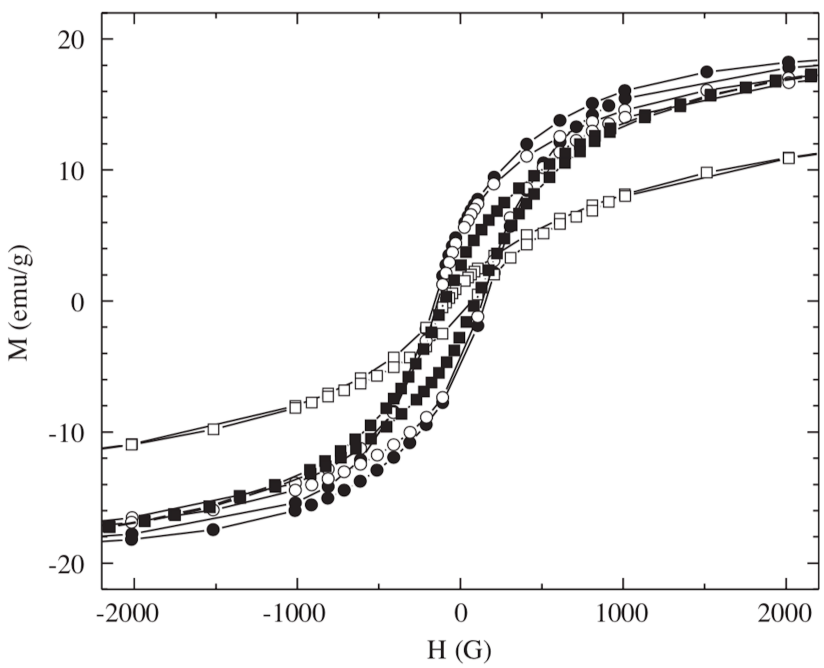

Figure 6: Hysteresis loops of the samples in series $20 \mathrm{G}$ heat-treated at temperatures from $600-1100^{\circ} \mathrm{C}$. $\circ$ sample $20 \mathrm{G}$, $\bullet$ sample $20 \mathrm{G}$ 600 , sample 20G1000, $\square$ sample 20G 1100 . M-H measurements were conducted at room temperature in magnetic fields up to $2 \mathrm{kG}$, corresponds to their initial $\mathrm{Fe}_{2} \mathrm{O}_{3}$ content ( $\mathrm{X}=0.20 \%$ mole) [75].

rather than other materials, functioning as an oxygen barrier, protecting the magnetite in the glass-ceramic from oxidizing.

Hernández et al. [123] studied a 20\%wt $\mathrm{Fe}_{2} \mathrm{O}_{3}$ containing biphasic material that was obtained by mixing two glasses (prepared by different routes). One of them by solgel and the other by melting, achieving a biphasic material that was sintered under $\mathrm{N}_{2}$ atmosphere to avoid the formation of nonmagnetic iron phases. The combination of these glasses offered the possibility of designing a material with the desired features for HT treatment. The bioactive behavior was attributed to the sol-gel glass content. The crystallization of the glass-ceramic provided the magnetic phase, and the coercive force increased when the solgel glass was added. The sol-gel glass content modified the coercive force, so that hyperthermic performance was improved [123].

This heat-generating property that has been conferred on bioactive ceramics makes possible to apply them to the treatment of tumors [137]. After the exposure of the patient to a magnetic field, it is expected that the glass-ceramic bioactive properties can act as a bone graft and that the heat-generating act as cancer treating agent. For that, several in vitro, in vivo and clinical trials yet have to be performed. 


\subsection{Iron silicates}

A magnetic glass-ceramic suitable to be used as biomaterial was synthesized for Vallet-Regí et al. [139] After the $\mathrm{NaO}-\mathrm{Fe}_{2} \mathrm{O}_{3}-\mathrm{CaO}-\mathrm{SiO}_{2}$ starting glass is annealed, a glass-ceramic based on Ferro and wollastonite like and $\epsilon$-(Fe, $\mathrm{Ca}) \mathrm{SiO}_{3}$ like phases is obtained. Both phases contain $\mathrm{Fe}^{2+}$ ions, leading to two magnetic phases with different coercive forces. The results show that magnetic glass would be used as a biomaterial for bone substitution, in the hyperthermia treatment.

While in the Goel et al. [140] work the studied the synthesis and characterization of magnetic glass-ceramics along diopside $\left(\mathrm{CaMgSi}_{2} \mathrm{O}_{6}\right)$-aegirine $\left(\mathrm{NaFeSi}_{2} \mathrm{O}_{6}\right)$. The activation energy of crystallization decreased with increasing $\mathrm{Na}$ and $\mathrm{Fe}$ content in the glasses, and the investigated glass-ceramics exhibited a small amount of ferromagnetic behavior, especially noticeable at low magnetic fields. They don't report any study of bioactivity behavior.

\subsection{Iron phosphate}

Singh et al. study the bioactivity and magnetic properties in glass and glass ceramics based on the $\mathrm{SiO}_{2}-\mathrm{Na}_{2} \mathrm{O}$ $\mathrm{Fe}_{2} \mathrm{O}_{3}-\mathrm{CaO}-\mathrm{P}_{2} \mathrm{O}_{5}-\mathrm{B}_{2} \mathrm{O}_{3}$. The glass-ceramic samples exhibit $\mathrm{Na}_{3} \mathrm{CaSi}_{3} \mathrm{O}_{8}$ and $\mathrm{Na}_{3-\chi} \mathrm{Fe}_{X} \mathrm{PO}_{4}$ phases. After dipping the glass-ceramic samples in a simulated body fluid, silica hydrogel first forms, followed by an amorphous calcium phosphate layer. Magnetic and microwave resonance experiments further demonstrate the potential of these glassceramics for possible use in hyperthermia [141].

In another research conducted by Singh et al. [82], magnetic properties of glass-ceramics derived from glasses with composition $41 \mathrm{CaO}-(52-\mathrm{x}) \mathrm{SiO}_{2}-4 \mathrm{P}_{2} \mathrm{O}_{5}-3 \mathrm{Na}_{2} \mathrm{O}$ $x \mathrm{xe}_{2} \mathrm{O}_{3}$ were evaluated as a function of $\mathrm{Fe}_{2} \mathrm{O}_{3}$ content. A structural investigation revealed the presence of nanocrystalline magnetite in the heat-treated samples contain ing $\mathrm{x} \geq 2 \mathrm{~mol} \% \mathrm{Fe}_{2} \mathrm{O}_{3}$. Biocompatible crystalline phases as hydroxyapatite $\left(\mathrm{Ca}_{10}\left(\mathrm{PO}_{4}\right)_{6}(\mathrm{OH})_{2}\right)$ and wollastonite $\left(\mathrm{CaSiO}_{3}\right)$ were also identified in all the heat-treated samples [60]. In this work, evaluation of some magnetic properties as a function of iron oxide concentration was interpreted by of the variation in the saturation magnetization, coercivity and the area under the hysteresis loop. Generally, samples with $\mathrm{x} \geq 2 \mathrm{~mol} \%$ of iron oxide exhibited magnetic behavior similar to soft magnetic materials with narrow hysteresis loop and low coercivity. Results showed that the coercivity of the samples decreased with increasing $\mathrm{Fe}_{2} \mathrm{O}_{3}$ concentration. Moreover, the saturation magnetization and the area under the hysteresis loop increased with increasing $\mathrm{Fe}_{2} \mathrm{O}_{3}$ content. Since the area under the loop is proportional to the energy loss and hence to the heat generated by a magnetic sample under an alternating field, materials with higher $\mathrm{Fe}_{2} \mathrm{O}_{3}$ concentration are capable of producing more heat. Consequently, these magnetic bioactive glass-ceramics are expected to be useful for localized hyperthermia treatment of cancer [82].

\subsection{Co-doped $\mathrm{TiO}_{2}$}

Nakamura et al. [142] work in the Co ion doped phaseseparated glass-ceramics in the composition of $48.5 \mathrm{TiO}_{2}$ $48.5 \mathrm{SiO}_{2}-3 \mathrm{Al}_{2} \mathrm{O}_{3}(\mathrm{~mol} \%)$ was prepared by the meltquenching method. All prepared samples consisted of the $\mathrm{TiO}_{2}$ rutile phase of fine particulate and the $\mathrm{SiO}_{2}$-rich glassy phase. The particle sizes of the samples of $x=0$ and 0.5 were $200-400 \mathrm{~nm}$ in diameter, and those of $\mathrm{x}=1.5$ and 2.5 were $500-1000 \mathrm{~nm}$ in diameter. The room temperature ferromagnetic property was observed for the samples containing 1.5 and $2.5 \mathrm{~mol} \%$ of $\mathrm{CoO}$, which was accompanied by the paramagnetic behavior at a high magnetic field. The electric conductivity was also observed in all samples, but the conductivity steeply decreased with an increase of the Co ion content. Their conduction behavior was similar to that of a semiconductor from their temperature dependence, which is expected from the character of $\mathrm{TiO}_{2}$ as an n-type semiconductor.

\subsection{Glass/Glass-ceramic composites}

Arcos et al. [120] using the composition $45 \mathrm{SiO}_{2}-45 \mathrm{CaO}$ $10 \mathrm{Fe}_{2} \mathrm{O}_{3}(\mathrm{~mol} \%)$ for the glass made in the meltingquenching route, $58 \mathrm{SiO}_{2}-36 \mathrm{CaO}-6 \mathrm{P}_{2} \mathrm{O}_{5}(\mathrm{~mol} \%)$ for the glass made in the route sol-gel obtained two glasses by a different path, sol-gel, and melting, and finally a biphasic glass-ceramic with these two glasses. While the glass made by the sol-gel route needs lower times in contact with SBF to show bioactivity, the glass made by melting shows better magnetic properties. One inherent disadvantage of the sol-gel process is that the incorporation of $\mathrm{Fe}$ is complicated and the segregation of the non-magnetic iron phase can readily occur. The biphasic material shows magnetic properties and high in vitro bioactivity. The combination of two different phases (sol-gel-derived glass and magnetic glass-ceramic), supplies both properties [120].

In a subsequent study by Arcos et al. [121] three biphasic materials were synthesized from a magnetic glassceramic (Si-Ca-Fe) and a bioactive sol-gel glass (Si-P-Ca). The ratios of glass-ceramic sol-gel glass used in this work 
were 1:1, 2:1, and 5:1. These materials show bioactive and magnetic properties and can be used as thermoseeds for hyperthermia treatment of bone tumors. The sol-gel glass content affects the textural properties of the glass-ceramic, giving rise to porosity, which plays a fundamental role in the formation of an apatite-like layer on the surface. On the other hand, as the sol-gel glass content increases, the magnetic properties change due to the diffusion of Fe ions to the glassy phases of the biphasic materials. The biphasic nature of these materials allows the changing of both properties, depending on the requirements of the patient.

In the composite of Ruiz et al. [123] implantable thermoseeds are synthesized from mixtures of a melt-derived glass with composition $\mathrm{SiO}_{2}$ (40)- $\mathrm{CaO}(40)-\mathrm{Fe}_{2} \mathrm{O}_{3}(20)$ (mol\%) and a sol-gel glass with composition $\mathrm{SiO}_{2}(58)-$ $\mathrm{P}_{2} \mathrm{O}_{5}(6)-\mathrm{CaO}(36)$ (mol\%). Structural, textural and magnetic properties of the samples are evaluated. In vitro bioactivity is assessed to determine the potential capability to bond to living bone. In the bioactivity assay, the release of $\mathrm{Ca}^{2+}$ to the SBF and the rise in $\mathrm{pH}$ are in agreement with the mechanism proposed by Kokubo [143] for the formation of carbonate hydroxyapatite on the surface of bioactive glasses and glass-ceramics. This behavior is acceptable to indicate potential in vivo capability of the material to bond to bone. The sol-gel glass in the composition is responsible for the bioactivity. It partially dissolves in contact with SBF, so that an exchange of $\mathrm{Ca}^{2+}$ and $\mathrm{H}_{3} \mathrm{O}^{+}$of the SBF is produced. This positive results for the bioactivity was reported too in the study of Liu et al. [88] a bioactive and magnetic biphasic material for hyperthermia application has been synthesized. The biphasic material is obtained from a mixture 1:1 of ferromagnetic glassceramic and $45 \mathrm{~S} 5$ bioactive glass sintered at $920^{\circ} \mathrm{C}$ covered by graphite. The hydroxyl carbonate apatite is observed on the surface of biphasic material soaked in SBF at $36.5^{\circ} \mathrm{C}$ up to 10 days. Whereas its bioactive behavior is due to the melt-derived $45 \mathrm{~S} 5$ bioactive glass, the presence of single magnetite phase included in the ferromagnetic glassceramic provides magnetic property. It can be useful for hyperthermia treatment of cancer. This biphasic material supplies many possibilities for this kind of therapy.

Li et al. [128] reported a composite bioactive and magnetic glass-ceramic in the system $\mathrm{CaO}-\mathrm{SiO}_{2}-\mathrm{P}_{2} \mathrm{O}_{5}-\mathrm{MgO}-$ $\mathrm{CaF}_{2}-\mathrm{MnO}_{2}-\mathrm{Fe}_{2} \mathrm{O}_{3}$ was synthesized by doping $\mathrm{MnO}_{2}$ and $\mathrm{Fe}_{2} \mathrm{O}_{3}$ to wollastonite-fluor- apatite-containing glassceramics. And $\mathrm{MnFe}_{2} \mathrm{O}_{4}$ and $\mathrm{Fe}_{3} \mathrm{O}_{4}$ were detected to be the magnetic phases of the novel material. Under a magnetic field of $10, \mathrm{kOe}$, the saturation magnetization and coercive field of the sample were $6.4 \mathrm{emu} / \mathrm{g}$ and 198 Oe, respectively. Though the doping of oxides decreased the bioactivity of the material, a lot of hydroxyapatite containing $\mathrm{CO}_{3}^{2-}$ were observed on the surface of MG after soaking in SBF for 14 days. The experiment of co-culturing ROS17/2.8 cells with material showed that the cells could successfully attach and well proliferate on the surface of MG, and MG showed better cell affinity than the original matrix. The material has the potential to be used as thermoseeds for hyperthermia.

\subsection{Polymer/Glass-ceramic composites}

Takegami et al. [144] developed a ferromagnetic bone cement as a thermoseed to generate heat by hysteresis loss under an alternate magnetic field. Samples with a portion of the bioactive glass-ceramic component replaced by magnetite $\left(\mathrm{Fe}_{3} \mathrm{O}_{4}\right)$ powder were produced. The temperature of this thermoseed rises in proportion to the weight ratio of magnetite powder, the volume of the thermoseed, and the intensity of the magnetic field. The heat-generating ability of this thermoseed implanted into a rabbit and human cadaver tibiae was investigated by applying a magnetic field with a maximum of 300 Oe and $100 \mathrm{kHz}$. In this system, it was effortlessly to increase the temperature of the thermoseed in bone beyond $50 \pm 7^{\circ} \mathrm{C}$ by adjusting the above-mentioned control factors. When the temperature of the thermoseed in rabbit tibiae was maintained at 50 to $60^{\circ} \mathrm{C}$, the temperature at the interface between the bone and muscle (cortical surface) surrounding the material rose to 43 to $45^{\circ} \mathrm{C}$; and at a distance of $10 \mathrm{~mm}$ from the thermoseed in the medullary canal, the temperature did not exceed $40^{\circ} \mathrm{C}$. These results indicate that this ferromagnetic bone cement could be applicable for the hyperthermic treatment of bone tumors.

Another composite with positive results was reported for Bruno et al. [145], a material intended to be applied as bone filler for the hyperthermic treatment of bone tumors. The ferrimagnetic bioactive glass-ceramic belongs to the system $\mathrm{SiO}_{2}-\mathrm{Na}_{2} \mathrm{O}-\mathrm{CaO}-\mathrm{P}_{2} \mathrm{O}_{5}-\mathrm{FeO}-\mathrm{Fe}_{2} \mathrm{O}_{3}$ and contains magnetite $\left(\mathrm{FeO}^{\star} \mathrm{Fe}_{2} \mathrm{O}_{3}\right)$ inside an amorphous bioactive residual phase (in a PMMA matrix). A calorimetric analysis demonstrated the cement ability to generate heat under an alternate magnetic field.

\subsection{Other composites}

Konaka et al. [146] prepared a composite of a glass containing $19.50 \mathrm{Fe}_{2} \mathrm{O}_{3}, 40.25 \mathrm{CaO}, 40.25 \mathrm{SiO}_{2}$ (mol\%) in which metallic $\alpha$-Fe precipitated by heat treatment above $700^{\circ} \mathrm{C}$ under $\mathrm{H}_{2}$ atmosphere. The crystallite size and molar fraction increased with increasing treatment temperature to 
reach about $150 \mathrm{~nm}$ and $17 \mathrm{~mol} \%$, respectively, at $1150^{\circ} \mathrm{C}$. The maximum heat generation reached about $150 \mathrm{~W} \cdot \mathrm{g}^{-1}$ at $850^{\circ} \mathrm{C}$.

Ei Khesen et al. [147] made three samples of glass/ceramic composites from bioactive phosphate glass and iron oxide. The samples contained 30, 50, and 70 mass- $\% \mathrm{Fe}_{2} \mathrm{O}_{3}$. Formation of hematite in the glass matrix will likey allow them to be responsive to a magnetic field. In that study study, the addition of bioactive glass to the magnetic ceramic yielded bioactive properties, which are beneficial for implantation. Two phases - sodium phosphate and calcium phosphate - are responsible for the bioactive behavior.

Leenakul et al. [148] developed a material from the $\mathrm{BaFe}_{12} \mathrm{O}_{19}$ - 45S5 glass system were successfully prepared using the incorporation method. Even though the $\mathrm{BaFe}_{12} \mathrm{O}_{19}$ phase was found to decompose during melting forming $\mathrm{Fe}_{3} \mathrm{O}_{4}$, this phase remained in the quenched glass samples and is known to play an essential role in the magnetic properties. They found that after applying a magnetic field of $10 \mathrm{kOe}$, the glass-ceramic samples exhibited soft magnetic properties. All the samples showed good bioactivity in vitro, as shown by the formation of an apatite phase. The addition of $\mathrm{BaFe}_{12} \mathrm{O}_{19}$ to bioglass $45 \mathrm{~S} 5$ could improve both the magnetic properties and the bioactivity of this material.

In their subsequently work, Leenakul et al. [149] prepared ferrimagnetic bioactive glass-ceramics from the $\mathrm{BaFe}_{12} \mathrm{O}_{19}(\mathrm{BF})-\mathrm{SiO}_{2}-\mathrm{CaO}-\mathrm{Na}_{2} \mathrm{O}-\mathrm{P}_{2} \mathrm{O}_{5}$ (45S5) system using the so-caller incorporation method. In this method, $\mathrm{BF}$ crystals were first produced using the solid-state reaction technique and then added to the glass precursor glass as a batch, which was then further mixed and sintered to form the composite [149]. From structural characterization, two major phases, sodium calcium silicate $\left(\mathrm{Na}_{2} \mathrm{Ca}_{2} \mathrm{Si}_{3} \mathrm{O}_{9}\right)$ and barium iron oxide $\left(\mathrm{BaFe}_{12} \mathrm{O}_{19}\right)$ were identified in all of the sintered samples containing BF [149]. To evaluate the potential of these materials for hyperthermia treatment of cancer, magnetic hysteresis loops of the samples were obtained. They found that the saturation magnetization increases with an increase in the $\mathrm{BF}$ content because of its dependence on the magnetic phase concentration. On the other hand, since the BF crystallite has a multi-domain structure; the coercivity of the samples decreases with increasing amounts of $\mathrm{BF}$ in the samples. Moreover, it was shown that, for an applied field of $\pm 10 \mathrm{kOe}$, the area of the hysteresis loop increased with the content of barium ferrite from 5 wt. $\%$ to 40 wt. $\%$ [149].

In the work of Liu et al. [150], a porous ferromagnetic glass-ceramic containing magnetite has been synthesized. The hydroxyapatite prepared via precipitation on a biolog- ical template is an excellent foaming agent in this system. The appropriate mass proportion of ferromagnetic glassceramic and HA is $85: 15$. This material was obtained by treatment at $1000^{\circ} \mathrm{C}$ for 1 hour in a graphite mold. The ferromagnetic glass-ceramic contains pores with a diameter of 30-50 $\mu \mathrm{m}$ distributed uniformly. The authors mentioned that it could potentially be used as drug carrier, therefore this material has a dual function - thermal therapy and chemotherapy for treatment of tumors.

\section{In vitro studies}

\subsection{Acellular tests using SBF}

In vitro experiments using a simulated body fluid (SBF), consist in subjecting the material samples in the fluid which have ion concentrations, $\mathrm{pH}$ and temperature almost equal to the human blood plasma, this is preliminary, selective and inexpensive tests, which are the first step to lead to other experiments in vitro and in vivo which have higher costs and specialized professionals for breeding, implantation and sacrificing of animals to collect samples for analysis.

It is possible to evaluate the bioactivity of a material by examining the formation of hydroxycarbonate apatite (HCA) on its surface; a type of surface that is not formed on inert glass-ceramics, therefore, it is considered an essential condition for an artificial material to bond to living bone in body environment [151]. Among the studies on glass-ceramics for the HT covered in this review paper, approximately $70 \%$ of them reported in vitro tests using the SBF solution. All studies indicated the precipitation of the hydroxyapatite layer. However, some tested materials presented a decrease in the bioactivity due to the foreign oxide added to induce magnetic behavior. In the next paragraphs we will review in vitro studies.

In the work of Leenakul et al. [112] a positive effect on the bioactivity was observed in samples sintered at $850^{\circ} \mathrm{C}$, in a glass matrix $24.5 \mathrm{Na}_{2} \mathrm{O}-24.5 \mathrm{CaO}-45 \mathrm{SiO}_{2}-6 \mathrm{P}_{2} \mathrm{O}_{5}(\mathrm{wt} \%)$, and the addition of calcined barium ferrite $\mathrm{BaFe}_{12} \mathrm{O}_{19}$ (BF) at 5, 10, 20, and $40 \mathrm{wt} \%$. The glass-ceramic samples after being sintered with various BF contents and temperatures between 800 e $900^{\circ} \mathrm{C}$, result reveals the presence of sodium calcium silicate, $\mathrm{Na}_{2} \mathrm{Ca}_{2} \mathrm{Si}_{3} \mathrm{O}_{9}$ and barium iron oxide $\mathrm{BaFe}_{12} \mathrm{O}_{19}$. The crystals of $\mathrm{Na}_{2} \mathrm{Ca}_{2} \mathrm{Si}_{3} \mathrm{O}_{9}$, and $\mathrm{BaFe}_{12} \mathrm{O}_{19}$ that could act as nucleation agents increasing the biokinetic [112], which is consistent with the work of Filho et al. [152] who reported in his study that the increase 
in the amount of crystalline phase leads to an increase in the formation time of the hydroxyapatite layer.

The inclusion of some oxides decreases the rate of apatite formation in SBF, like was mention in the study of Sharma et al. [93], in which the increasing of $\mathrm{Fe}_{2} \mathrm{O}_{3}$ content in the glass-ceramics suppressed the dissolution of calcium, thus inhibiting the formation of the silica gel layer, hence the rate of apatite formation (bioactivity) is reduced. The presence of magnetite and trace of residual iron ions into the glassy matrix can cause a slow bioactive kinetics of the glass-ceramic, this phenomenon was also observed by Verne et al. [132] in their studies of ferrimagnetic glassceramic. The effect of iron on bioactivity (the more Fe, less bioactivity) was also investigated by Abe et al. [116]. The same behavior was observed using others oxides such as $\mathrm{Mg}$ ferrite, used in the study of Li et al. [114].

Singh and Srinivasan $[98,99]$, in 2010, showed bioactivity and the apatite formation on the surface these ferrimagnetic glass-ceramics (FGC). Moreover, an increase in bioactivity was observed with an increase in zinc-iron oxide content in the reported series of glasses [100,153]. Shah et al. [102] also studied FGC's immersion in SBF for three weeks. The results confirmed the precipitation of hydroxyapatite, suggesting that the obtained FGC were bioactive and could possibly bond to living tissues in the physiological environment $[97,103]$. This results also were presented in the work of Yumin et al. [105] were the SEM and EDS analyses were conducted on magnetic composites; the formation of hydroxyapatite after immersion in SBF was confirmed and cell culture experiments showed that the material promoted osteoblast proliferation.

In 2013, Leenakul et al. [107] investigated the in vitro bioactivity in a $\mathrm{SrFe}_{12} \mathrm{O}_{19}-\mathrm{SiO}_{2}-\mathrm{CaO}-\mathrm{Na}_{2} \mathrm{O}-\mathrm{P}_{2} \mathrm{O}_{5}$ glassceramic, a hydroxycarbonate apatite layer was found on the surface of all bioglass-ceramics after 14 days in SBF solution, confirming their bioactivity and it increased with the strontium ferrite content. Jagadish et al. [113], however, reported the absence of the apatite layer formation on a Caferrite based glass-ceramic, even after 8 days.

\subsection{Cellular tests}

Seung Oh et al. [32], in their work prepared ferrimagnetic glass ceramics in the system $40 \mathrm{Fe}_{2} \mathrm{O}_{3}-30 \mathrm{CaO}-30 \mathrm{SiO}_{2}$ and precipitated ferrimagnetic crystallites through controlled two-step heat treatment. Cell viability tests were conducted in L-929 cells that showed that both as-quenched and heat-treated glasses were biocompatible and no cytotoxicity [32].
In the study of Alcaide et al. [134] the authors could produce local hyperthermia on cultured human osteosarcoma Saos-2 cells successfully. The cells were seeded in DMEM for 4 days and the results pointed out that the upper limit of moderate hyperthermia, between 41 and $43^{\circ} \mathrm{C}$, could be reached. In this temperature range, malignant cells die, whereas healthy cells don't undergo significant or nonreversible damage.

In the work of Gamal-Eldeen et al. [154], the cytotoxicity of ferrimagnetic glass-ceramic nanocomposites (with high content of magnetite $~ 60 \%$ ) were explored. Saos-2 cells were incubated with the material (in a $100 \mu \mathrm{g} / \mathrm{ml}$ ratio) and treated in the presence and absence of magnetic field using a permanent magnet $(0.5 \mathrm{~T}, 80 \times 40 \times 10 \mathrm{~mm})$. Results indicated that the composites inhibited cell viability and there was no influence of magnetism on their cytotoxicity.

In the studies of Wang et al. [155], $\mathrm{Fe}_{2} \mathrm{O}_{3}-\mathrm{CaO}-\mathrm{SiO}_{2}$ glass ceramics doped with $\mathrm{TiO}_{2}$ and $\mathrm{P}_{2} \mathrm{O}_{5}$ showed a negative influence on the cell viability mostly on samples with $\mathrm{TiO}_{2}$. While $\mathrm{TiO}_{2}$ had some adverse effect on the cell viability, $\mathrm{P}_{2} \mathrm{O}_{5}$ had little impact on the cell viability over a specific concentration range.

Bretcanu et al. [156], studied cell adhesion and proliferation of 3T3 murine fibroblasts when in contact with ferrimagnetic glass-ceramics from the system $24.7 \mathrm{SiO}_{2}-$ $13.5 \mathrm{Na}_{2} \mathrm{O}-13.5 \mathrm{CaO}-3.3 \mathrm{P}_{2} \mathrm{O}_{5}-14 \mathrm{FeO}-31 \mathrm{Fe}_{2} \mathrm{O}_{3}$ (wt.\%). Cytotoxicity was performed by qualitative evaluation of human bone osteosarcoma cells U2OS cell line. The in vitro tests were carried out by using two sets of samples: samples pretreated in a simulating body fluid (SBF) and samples without the pre-treatment. The adhesion test presented no significant differences between the untreated and SBF treated samples in the first hours of incubation however, differences appeared after one day of cell culture. About $80 \%$ more cells were attached to the pre-treated samples after 3 days of incubation, compared to the untreated samples. The proliferation test indicated that 3T3 cells proliferated almost two times more on the samples pretreated in SBF. Also, a decrease of confluence was observed at 48 and $72 \mathrm{~h}$ for U2OS cells exposed to the untreated glass-ceramic samples.

In the study of Miola et al. [157], composite bone cements (based on PMMA loaded with ferrimagnetic and bioactive glass-ceramic particles) were biologically characterized after a magnetic induction heating using both tumoral osteosarcoma cells and not tumoral fetal osteoblast cells. Cytocompatibility (MTT assay) and cells proliferation were evaluated using human osteosarcoma-like cells (MG63, ATCC CRL1427) and human foetal osteoblasts (hFOB 1.19, ATCC CRL11372). For the in vitro hyperthermia 
assays, the specimens were treated using the magnetic induction furnace (Egma 6) generating an applied magnetic field intensity of 226 Oe. Specimens were treated for 5-1015-20 and 30 minutes under alternate magnetic field. Then, cells viability was evaluated by the MTT assay. Results revealed that the samples were biocompatible for both cell lines (MG63 and hFOB) and the in vitro hyperthermia tests indicated that after 15-20-30 minutes of heating, the MG63 cells viability started to decrease significantly. The authors indicated that the tumoral cells death occurred mainly by apotosis, specially for the longest exposure time, $30 \mathrm{~min}$, and that the viability of non-tumor cells was preserved.

\section{In vivo studies}

In vivo experiments evaluating the biocompatibility and bone bondign ability of a glass-ceramic, in the system (28-49) CaO-(28-51) $\mathrm{SiO}_{2}-(0-40) \mathrm{Fe}_{2} \mathrm{O}_{3}-(0-3) \mathrm{Na}_{2} \mathrm{O}-(0-3) \mathrm{B}_{2} \mathrm{O}_{3}$ (0-3) $\mathrm{P}_{2} \mathrm{O}_{5}$ (wt\%), were carried out by Ohura et al. [137]. The grafting procedure was performed by the implantation of rectangular plates of the glass and glass-ceramic into the metaphyses of the tibiae of 20 mature male rabbits. After 8 and 25 weeks the failure load necessary to detach the implant from the bone was measured using Nakamura's method [137] and histomorphometry was also conducted. To investigate the bone-heating ability of their glass-ceramic material, particles with a diameter range of 2-3 $\mathrm{mm}$ were inserted into the bone marrow through a drilled hole in the tibia1 metaphysis of each of 15 mature male rabbits (approximately $0.9 \mathrm{~g}$ were used). Immediately after the implantation, the leg containing the glassceramic granules was placed in the C-type troidal core of a gap-type induction generator and heated using 3000e, $100-\mathrm{kHz}$ alternating magnetic field. The temperature of the glass-ceramic and the the bone was measured by three fluoroptic thermometers inserted into the area containing granules and at the interface between the bone and muscle. Histomorphometry indicated that new bone was formed on the surfaces of both glass and glass-ceramic materials. The heating tests showed that it was possible to maintain the temperature of the glass-ceramic precisely at $45^{\circ} \mathrm{C}$ for $30 \mathrm{~min}$ and that the temperature at the interface between the bone and muscle could be increased to $42 \mathrm{C}$ successfully.

Matsumoto et al. [158] studied the implantation of a magnetic glass-ceramic composed of magnetite and wollastonite as a thermoseed for ocular hyperthermia. In this study, two groups of rabbits were used. Group A had five rabbits (five eyes) in which the temperature during hyper- thermia was measure and group B had six rabbits (six eyes) that were used to study the retinal toxicity of the hyperthermia by histologic examination. Results showed that the retinal surface was heated to $43.5^{\circ} \mathrm{C}$ in less than $7 \mathrm{~min}$ without heating the surrounding tissue. Additionally, the presented heating system showed a good temperature stability $\left(+0.1^{\circ} \mathrm{C}\right)$ under steady-state conditions. No thermotoxic effects in the adjacent retina, sclera, lens or other ocular structures were apparent on biomicroscopic or histologic examination.

\section{The ideal material for cancer treatment by hyperthermia}

Given the scarcity of in vivo and clinical studies, the actual effectiveness of the materials so far developed for the treatment of cancer tumors is still open. Considering the above summary experimental data, we present an attempt to describe the ideal characteristics of a material to be used in HT.

- Magnetic properties: glass-ceramics intended for cancer treatment by hyperthermia must contain of at least one ferro- or ferrimagnetic crystalline phase. That phase must present a high saturation magnetization (Ms) and a large area under the hysteresis loop. The larger Ms and the area inside the loop, the higher the magnetic loss, which releases energy in the form of heat; therefore, a smaller quantity of material can be used. As indicated by Borelli et al. [65], for clinical applications, the ideal response of a magnetic material to an external magnetic field would be to release sufficient heat at the lowest possible frequency and external magnetic field strength, also the material must undergo significant reversal magnetization (open-type hysteresis loop) at modest magnetic field to minimize the eddy current and 'shock' side-effects [65]. Another interesting feature would be a designed low Curie temperature, in particular around $43^{\circ} \mathrm{C}$, in which the material become non-magnetic and produce no heat when heated above a certain temperature, thereby allowing automatic temperature regulation and avoiding damage to the surrounding tissues.

- Particle size: the particle size will depend on the application. Submicron size particles show the same magnetic characteristic of a bulk material.

- Biocompatibility and deliverability: naturally, the material should not be toxic and/or induce an 
exacerbated inflammatory response from the surrounding tissues when implanted. Considering that the material could be injected directly into the bloodstream, it should exhibit no hemolytic activity, i.e., no damage to the red blood cells membrane;

- Bioactivity: if the overall purpose is not only to eliminate the tumor but also to regenerate the tissue, as it has been suggested for treatment of bone neoplasia, it is desirable that the material shows bioactive properties and induce a positive and specific response from the body.

- Resorbability: after having fulfilled its function, the material's bioactive phase should preferably gradually be resorbed by the body;

\section{Major challenges and future perspectives}

Despite the considerable number of publications on in vitro and in vivo aspects of HT, there are numerous uncertainties in correlating these results to clinical practice. This is especially true when we consider glass-ceramics for HT, since there are very few pre-clinical studies.

To develop new useful materials for cancer HT, an understanding of the relationship between physicochemical characteristics (e.g., crystalline(s) phase(s), microstructure, particle size and shape, impurities, etc.) and magnetic properties is indispensable. Although many efforts have been made, some ideal features of the materials are yet to be established, such as the ideal particle size and shape, the ideal routes of entry and clinical application (whereas subcutaneous, intraperitoneal, intramuscular or intravenous), the ideal applied-field strengths etc. In general, it is well accepted that Ms is proportional to the volume of the particle when particles of the same crystalline phase but with distinct sizes and shapes are compared [36]. This has been attributed to the reduction of the surfaceto-volume ratio and, consequently, decrease of the surface spin disorder. One of the last crucial steps for clinical application of magnetic hyperthermia remains the temperature control because heat conduction and energy adsorption in vivo are still not understood. Accurate temperature control is essential since overheating can damage the healthy tissue surrounding the tumor. Monitoring temperature using a non-invasive method may solve this problem. For instance, this monitoring could be made through magnetic resonance imaging, as suggested by Mornet et al. [13].

Magnetite, for example, the most studied magnetic phase has a high Curie temperature $\left(\mathrm{Tc} \sim 577^{\circ} \mathrm{C}\right)$. Theoret- ically, under an applied alternating magnetic field, the local temperature of a tumor containing magnetite particles could rise indefinitely until Tc is reached. This makes the local temperature control in clinical practice impossible. A wise way to control the temperature would be to design magnetic crystalline phases with low Curie temperature. Above Tc, the material loses its ferro- or ferrimagnetic behavior, and there is no further heat release by hysteresis loss. Therefore, Tc would be the maximum temperature reached by the magnetic particles. Tc of manganates in the $\mathrm{Ln}_{(1-x)} \mathrm{A}_{x} \mathrm{MnO}_{3}$ (where $\mathrm{Ln}=\mathrm{La}, \mathrm{Pr}, \mathrm{Nd}$ and $\mathrm{A}=\mathrm{Ca}, \mathrm{Sr}, \mathrm{Ba}$, $\mathrm{Pb}$ ) system, for example, strongly depend on the content and type of the bivalent ions. By varying the composition of the manganite, it is possible to obtain materials with Tc ranging from below zero to temperatures near $50^{\circ} \mathrm{C}[159]$.

Kuznetsov et al. [160] reported the synthesis of $\mathrm{La}_{0.8} \mathrm{Sr}_{0.2} \mathrm{MnO}_{3}, \mathrm{La}_{0.75} \mathrm{Sr}_{0.25} \mathrm{MnO}_{3}$ and $\mathrm{ZnFe}_{2} \mathrm{O}_{4}$ particles by freeze-drying. In an AC magnetic field (800 $\mathrm{kHz}, 90 \mathrm{Oe}$ ), the maximal temperature reached by $\mathrm{La}_{0.75} \mathrm{Sr}_{0.25} \mathrm{MnO}_{3}$ particles was $46.3^{\circ} \mathrm{C}\left(\mathrm{Tc} \sim 56^{\circ} \mathrm{C}\right)$ and $37.8^{\circ} \mathrm{C}$ for $\mathrm{La}_{0.8} \mathrm{Sr}_{0.2} \mathrm{MnO}_{3}$ particles $\left(\mathrm{Tc} \sim 48^{\circ} \mathrm{C}\right.$ ). The difference between Tc and the observed maximal temperature was attributed to the decrease of saturation magnetization. After 40 min of the application of magnetic field, no maximal temperature was found for $\mathrm{ZnFe}_{2} \mathrm{O}_{4}$ particles (Tc $100-102^{\circ} \mathrm{C}$ ), but the increase in temperature decreased as temperature increased; in this case, the rise in temperature is softer when compared to $\mathrm{Fe}_{3} \mathrm{O}_{4}$ particles.

An additional promising trend in this field is the combination of hyperthermia treatment with chemotherapeutic drugs. This could be possible through the surface functionalization of magnetic bioactive glass-ceramics, adding to this material drug delivery ability. Ferraris et al. [135] were the first to functionalize the surface of ferrimagnetic bioactive glass-ceramic particles. Surface functionalization of these materials with polyphenols is a challenging and innovative strategy to impart those additional functional and specific properties (e.g., antioxidant, anticancer and antibacterial). An inhibitory effect of various polyphenols (including gallic acid) on molecular mechanisms associated to chronic inflammation, tumor genesis, progression, invasion and metastasis, have been documented in vitro and in vivo. In this particular study, a glass with composition $24.7 \mathrm{SiO}_{2}-13.5 \mathrm{Na}_{2} \mathrm{O}$ $13.5 \mathrm{CaO}-3.3 \mathrm{P}_{2} \mathrm{O}_{5}-14 \mathrm{FeO}-31 \mathrm{Fe}_{2} \mathrm{O}_{3}$ (wt.\%) was heat-treated at $600^{\circ} \mathrm{C}$ for $12 \mathrm{~h}$ and a glass-ceramic composed of a bioactive glass matrix with embedded magnetite crystals was obtained (SC-45). After milling, the powder with particles smaller than $20 \mu \mathrm{m}$ was grafted with Gallic acid (GA).

Until the early 1980s, it was believed that bioactive materials only could bond to bones. Wilson et al. [161] first 
showed that soft connective tissues could also bond to 45S5 Bioglass ${ }^{\circledR}$. After Wilson, it has been further demonstrated that bioactive glasses and glass-ceramics can bond to a wide range of soft tissues, giving rise to applications that seemed impossible when Bioglass $45 \mathrm{~S} 5$ was first developed [50]. The capability of bioactive glasses and glassceramics to regenerate other types of tissues and organs is just beginning to be explored. This feature opened up new possibilities to expand the use of magnetic and bioactive glass-ceramics beyond bone cancer.

\section{Final considerations}

This review outlines 35 years of research on the main advances about bioactive magnetic glass-ceramics intended for cancer treatment by hyperthermia. All studies had a common objective: to design a material with double function, i.e., capable of killing cancer cells and regenerate the damaged tissue.

Magnetic glass-ceramics are indeed a very promising alternative to treat cancerous tumors, with minimal side effects. Many glass-forming systems and numerous magnetic crystalline phases have been investigated; however, their clinical use is still in the infancy. Therefore, given the scarcity of in vivo and clinical studies, these materials certainly warrant further research. We hope this review motivates students and researchers to pursue such type of study.

Acknowledgement: The authors are thankful to the Brazilian funding agencies CAPES and PPGCEM for granting a student fellowships to Martha Velasco, and to CNPq and The São Paulo Research Foundation - Fapesp (Center for Research, Technology and Education in Vitreous Materials - CEPID Process $n^{\circ}$ 07793-6) for funding this research work.

Ethical approval: The conducted research is not related to either human or animals use.

Conflict of Interests: The authors declare no conflict of interest regarding the publication of this paper.

\section{References}

[1] Szasz A., Szasz N., Szasz O., Oncothermia: Principles and Practices., Springer., 2010, 1, 566.
[2] Weinberg R.A., One renegade cell: how cancer begins, 1999, Basic Books.

[3] Mathews L.A., Cabarcas S.M, Hurt E.M., DNA repair of cancer stem cells, 2013, Springer.

[4] Hanahan D., Weinberg R.A., Francisco S., The Hallmarks of Cancer., Review University of California at San Francisco, 2000, 100, 57-70.

[5] Cetin I., Topcul M., Cancer stem cells in oncology., J. Buon., 2012, 17, 644-648.

[6] Oishi N., Wang X.W., Novel therapeutic strategies for targeting liver cancer stem cells,. Int. J. Biol. Sci., 2011, 7, 517-535.

[7] Topçul M., Çet I.i, N., An Innovative Therapeutic Approach in Oncology: Hyperthermia., 2013, 2, 73-80.

[8] Gottesman M.M., Fojo T., Bates S.E., Multidrug resistance in cancer: role of Atp-dependent transporters, 2001, 2, 1-11.

[9] Baronzio G., Hager E., Hyperthermia in cancer treatment: a primer, 2006, 1, 366.

[10] Behrouzkia Z., Joveini Z., Keshavarzi B., Eyvazzadeh N., Aghdam R.Z., Hyperthermia: How can it be used?, Oman Med. J., 2016, 31, 89-97.

[11] Habash R.W.Y., Bansal R., Krewski D., Alhafid H.T., Thermal therapy, Part 2: Hyperthermia techniques, Crit. Rev. Biomed. Eng., 2006, 34, 491-542.

[12] Wust P., Hildebrandt B., Sreenivasa G., Rau B., Gellermann J., Riess H., Review Hyperthermia in combined treatment of cancer, The Lancet-Oncology, 2002, 3, 487-497.

[13] Mornet S., Vasseur S., Grasset F., Duguet E., Magnetic nanoparticle design for medical diagnosis and therapy, J. Mater. Chem., 2004, 14, 2161-2175.

[14] Bieher Hairn I., Identification of Viable Regions in "in vitro" Spheroidal Tumors: A Mathematical Investigation, Louisiana Tech. Univ., 1981, 148, 71270, Ruston, Louisiana.

[15] Roussakow S., The history of hyperthermia rise and decline, Conf. Pap. Med., 2013, 1-40.

[16] Gilchrist R.K., Medal R., Shorey W.D., Hanselman R.C., Parrott J.C., Taylor C.B., Selective inductive heating of lymph nodes, Ann. Surg., 1957, 146, 596-606.

[17] Rand R.W., Snow H.D., Brown W.J., Thermomagnetic surgery for cancer., J. Surg Res, 1982,33, 177-183.

[18] Cherukuri P., Glazer E.S., Curley S.A., Targeted hyperthermia using metal nanoparticles, Adv. Drug. Deliv. Rev., 2010, 62, 339 . 345.

[19] Moroz P., Jones S.K., Gray B.N., Magnetically mediated hyperthermia: current status and future, Int. J. Hyperth., 2002, 18, 267-284.

[20] Jordan A., Scholz R., Wust P., Fähling H., Roland F., Magnetic fluid hyperthermia (MFH): Cancer treatment with AC magnetic field induced excitation of biocompatible superparamagnetic nanoparticles, J. Magn. Magn. Mater., 1999, 201, 413-419.

[21] Hildebrandt B., Wust P., Ahlers O., Dieing A., Sreenivasa G., Kerner T., The cellular and molecular basis of hyperthermia, Crit. Rev. Oncol. Hematol., 2002, 43, 33-56.

[22] Bettaieb A., Wrzal P.K., Averill-bates D.A., Hyperthermia: Cancer Treatment and Beyond, Cancer Treatm. Innov. Approaches, 2013, 2, 257-283.

[23] Höckel M., Vaupel P., Tumor hypoxia: definitions and current clinical, biologic, and molecular aspects, J. Natl. Cancer Inst., 2001, 93, 266-276.

[24] Gerweck L.E., Richards B., Jennings M., The influence of variable oxygen concentration on the response of cells to heat or $X$ 
irradiation, Radiat. Res., 1981, 85, 314-320.

[25] Streffer C., Biological basis of oncologic thermotherapy, 1990, 1, 7, Springer-Verlag, Berlin.

[26] Miola M., Pakzad Y., Banijamali S., Kargozar S., Vitale-Brovarone C., Yazdanpanah A., Glass-ceramics for cancer treatment: So close, or yet so far?, Acta Biomater., 2019, 83, 55-70.

[27] Kargozar S., Mozafari M., Hamzehlou S., Kim H., Baino F., Mesoporous bioactive glasses (MBGs) in cancer therapy: Full of hope and promise, Mater. Lett., 2019, 251, 241-246.

[28] Dickson J.A., Calderwood S.K., Infirmary R.V., Temperature range and selective sensitivity of tumors to hyperthermia: a critical review, Ann. N.Y. Acad. Sci., 1980, 335, 180-205.

[29] Henle K.J., Arrhenius analysis of thermal responses, Hyperth, Cancer Ther., 1983,47-53, GK Hall Medical Publishers, Boston.

[30] Karkan S.F., Mohammadhosseini M., Panahi Y., Milani M., Zarghami N., Akbarzadeh A., Magnetic nanoparticles in cancer diagnosis and treatment: a review, Artif Cells, Nanomed., Biotechnol., 2017, 45, 1-5.

[31] Bretcanu O., Vernè E., Cöisson M., Tiberto P., Allia P., Magnetic properties of the ferrimagnetic glass-ceramics for hyperthermia, J. Magn Magn Mater., 2006, 305, 529-533.

[32] Oh S.H., Choi S.Y., Lee Y.K., Kim K.N., Research on annihilation of cancer cells by glass-ceramics for cancer treatment with external magnetic field. I. Preparation and cytotoxicity, J. Biomed Mater. Res., 2001, 54, 360-365.

[33] Amirahmadi Z., Marghussian V.K., Beitollahi A., Mirkazemi S.M., Sarpoolaky H., Magnetite nanoparticles prepared by the crystallization of Na2O-Fe203-B203-SiO2 glasses., J. Noncryst. Solids, 2011, 357, 3195-3199.

[34] Coey J.M., Magnetism and magnetic materials, 2010, Cambridge Univ. Press.

[35] Morrish A.H., The Physical Principles of Magnetism., 1965, 1, 1-700, Wiley-IEEE Press.

[36] Kafrouni L., Savadogo O., Recent progress on magnetic nanoparticles for magnetic hyperthermia, Prog. Biomater., 2016, 5,14760 , Springer, Berlin.

[37] Bahadur D., Giri J., Biomaterials and magnetism, Sadhana, 2003, 28, 639-656.

[38] Gupta A.K., Gupta M., Synthesis and surface engineering of iron oxide nanoparticles for biomedical applications, Biomaterials, 2005, 26, 3995-4021.

[39] Karponis D., An arsenal of magnetic nanoparticles; perspectives in the treatment of cancer, Nanomedicine, 2016, 11, 2215-2232.

[40] Zia M., Phull A.R., Ali J.S., Synthesis, characterization, applications, and challenges of iron oxide nanoparticles, Nanotechnol. Sci. Appl., 2016, 49-67.

[41] Paulus J.A., Parida G.R., Tucker R.D., Park J.B., Corrosion analysis of $\mathrm{NiCu}$ and $\mathrm{PdCo}$ thermal seed alloys used as interstitial hyperthermia implants, Biomaterials, 1998, 18, 1609-1614.

[42] Mcnerny K.L., Kim Y., Laughlin D.E., Mchenry M.E., Mcnerny K.L., Kim Y., Chemical synthesis of monodisperse gamma -Fe -Ni magnetic nanoparticles with tunable Curie temperatures for self-regulated hyperthermia, 2010, 107, 312.

[43] Murray A.R., Kisin E., Inman A., Young S.H., Muhammed M., Burks T., Oxidative stress and dermal toxicity of iron oxide nanoparticles in vitro, Cell BioChem. Biophys., 2013, 67, 461-476.

[44] Lee J., Huh Y., Jun Y., Seo J., Jang J., Song H., Artificially engineered magnetic nanoparticles for ultra-sensitive molecular imaging, Nay Med., 2007, 13, 95-99.
[45] Kolhatkar A.G., Jamison A.C., Litvinov D., Willson R.C., Lee T.R., Tuning the magnetic properties of nanoparticles, Int. J. Mol. Sci., 2013, 14, 15977-16009.

[46] Berry C.C., Curtis A.S.G., Functionalisation of magnetic nanoparticles for applications in biomedicine, J. Phys. D Appl. Phys., 2003, 36, 198-206.

[47] Zeng H., Sun S., Li J., Wang Z.L., Liu J.P., Tailoring magnetic properties of core-shell nanoparticles, Appl. Phys. Lett., 2004, 85, 792-794.

[48] Larumbe S., Gómez-Polo C., Pérez-Landazábal J.I., Pastor J.M., Effect of a SiO2 coating on the magnetic properties of $\mathrm{Fe} 304$ nanoparticles, J. Phys. Condens. Matter., 2012, 24-26.

[49] Gordon R.T., Hines J.R., Gordon D., Intracellular hyperthermia - A biophysical approach to cancer treatment via Intracellular temperature and biophysical alterations, Med. Hypotheses, 1979, 5, 83-102.

[50] Owens D.E., Peppas N.A., Opsonization, biodistribution, and pharmacokinetics of polymeric nanoparticles, Int. J. Pharm., 2006, 307, 93-102.

[51] Asín L., Ibarra M.R., Tres A., Goya G.F., Controlled Cell Death by Magnetic Hyperthermia: Effects of Exposure Time, Field Amplitude, and Nanoparticle Concentration, Sprimger St., 2012, 1319-1327.

[52] Cervadoro A., Giverso C., Pande R., Sarangi S., Preziosi L., Wosik J., Design maps for the hyperthermic treatment of tumors with superparamagnetic nanoparticles, PLoS One, Public Library of Science, 2013, 857332.

[53] Gudoshnikov S.A., Liubimov B.Y., Usov N.A., Hysteresis losses in a dense superparamagnetic nanoparticle assembly, AIP Adv., 2012, 1401.

[54] Obaidat I.M., Issa B., Haik Y., Magnetic Properties of Magnetic Nanoparticles for Efficient Hyperthermia, Nanomater., 2015, 63 89.

[55] Pin Y., Rivas J., Ban M., Magnetic nanoparticles for application in cancer therapy, J. Magn Magn Mater., 2012, 324, 3499-3502.

[56] Gudoshnikov S.A., Liubimov B.Y., Usov N.A., Hysteresis losses in a dense superparamagnetic nanoparticle assembly Hysteresis losses in a dense superparamagnetic nanoparticle assembly, AlP advances, 2014, 2, 012143.

[57] Rabin Y., Is intracellular hyperthermia superior to extracellular hyperthermia in the thermal sense., Int. J. Hyperth., 2002, 18, 194-202.

[58] Borrelli N.F., Luderer A.A., Panzarino J.N., Ceramic suitable for inducing localised heating in the presence of a radio frequency magnetic field and use thereof., U.S. Patent No. 4,323,056. 1982, Washington, DC, U.S. Patent and Trademark Office.

[59] Hench L.L., Day D.E., Holand W., Rheinberger V.M., Glass and Medicine., Int. J. Appl. Glas. Sci., 2010, 1, 104-117.

[60] Baino F., Novajra G., Miguez-Pacheco V., Boccaccini A.R., VitaleBrovarone C., Bioactive glasses: Special applications outside the skeletal system, J. Non-Cryst. Solids., 2016, 432, 15-30.

[61] Rahaman M.N., Day D.E., Sonny Bal B., Fu Q., Jung S.B., Bonewald L.F., Bioactive glass in tissue engineering, Acta Biomater., 2011, 7, 2355-2373.

[62] Hoppe A., Guldal N.S., Boccaccini A.R., A review of the biological response to ionic dissolution products from bioactive glasses and glass-ceramics, Biomaterials, 2011, 32, 2757-2774.

[63] Montazerian M., Zanotto E.D., History and trends of bioactive glass-ceramics, J. Biomed. Mater., 2016, 1231-1249. 
[64] Deubener J., Allix M., Davis M.J., Duran A., Höche T., Honma T., Updated definition of glass-ceramics, J. Non-Cryst. Solids., 2018, 501, 3-10.

[65] Borrelli N.F., Luderer A.A., Panzarino J.N., Hysteresis heating for the treatment of tumours, Phys. Med. Biol., 1984, 29, 487-494.

[66] Luderer A.A., Borrelli N.F., Panzarino J.N., Mansfield G.R., Hess D.M., Brown J.L., Murine Mammary Carcinoma Glass-CeramicMediated, Magnetic-Field-induced Localized Hyperthermia: Response of a Murine Mammary Carcinoma, Radiation Res., 1983, 94, 190-198.

[67] Palazzo B., Scialla S., Scalera F., Margiotta N., Gervaso F., Nanos tructured Ceramics and Bioceramics for Bone Cancer Treatment General Concepts onto Bone Cancer and Bone Metastases., Adv. Compos. Mater., 2016, 209-273.

[68] Hench L.L., Bioactive Glasses and Glass-Ceramics, Mater. Sci. Forum, 1999, 293, 37-64.

[69] Kokubo T., Preparation and properties of composite ceramics for biomedical applications, J. Japan Soc. Powder Metall., 1990, 37, 324-328.

[70] Ebisawa Y., Sugimoto Y., Hayashi T., Kokubo T., Ohura K., Yamamuro T., Crystallization of ( $\mathrm{FeO}, \mathrm{Fe} 2 \mathrm{O} 3)-\mathrm{CaO}-\mathrm{SiO} 2$ glasses and magnetic properties of their crystallized products, J. Ceram. Soc. Japan, 1990, 99, 7-13.

[71] Ebisawa Y., Kokubo T., Ohura K., Yamamuro T., Bioactivity of \{Fe203-containing $\{\mathrm{CaO}-\mathrm{SiO} 2\}$ glasses: In vitro evaluation, J. Mater. Sci. Mater. Med., 1993, 4, 225-232.

[72] Ebisawa Y., Miyaii F., Kokubo T., Ohura K., Nakamura T., Bioactivity of ferrimagnetic glass-ceramics in the system FeO-Fe2O3CaO-SiO2, Biomaterials, 1997, 18, 1277-1284.

[73] Masakazu K., Hiroshi T., Tadashi K., Preparation of magnetitecontaining atmosphere for of cancer in controlled hyperthermia, J. Ceram. Soc. Japan, 2001, 109, 39-44.

[74] Eniu D., Cacaina D., Coldea M., Valeanu M., Simon S., Structural and magnetic properties of $\{\mathrm{CaO}-\mathrm{P} 2 \mathrm{O} 5-\mathrm{SiO} 2-\mathrm{Fe} 2 \mathrm{O}\}$ glassceramics for hyperthermia, J. Magn. Magn. Mater., 2005, 293, 310-313.

[75] Leventouri T., Kis A.C., Thompson J.R., Anderson I.M., Structure, microstructure, and magnetism in ferrimagnetic bioceramics, Biomaterials, 2005, 26, 4924-4931.

[76] Bretcanu O., Spriano S., Vitale C.B., Verné E., Synthesis and characterization of coprecipitation-derived ferrimagnetic glassceramic., J. Mater. Sci., 2006, 41, 1029-1037.

[77] Bretcanu O., Spriano S., Verne E., Tiberto P., Allia P., The influence of crystallised $\mathrm{Fe} 304$ on the magnetic properties of coprecipitation-derived ferrimagnetic glass - ceramics, Acta Biomater., 2005, 1, 421-9.

[78] Tiberto P., Coisson M., Vinai F., Allia P., Bretcanu O., Vernè E., Magnetic Relaxation in Ferrimagnetic Glass-Ceramics Obtained by Co-Precipitation at Different Temperatures, IEEE Trans. Magn., 2007, 43, 2471-2473.

[79] Singh R.K., Srinivasan A., Bioactivity of ferrimagnetic MgO - CaO - SiO2 - P2O5 - Fe2O3 glass-ceramics, Ceram. Int., 2010, 36, 283 290.

[80] Abdel-Hameed S.A.M., Hessien M.M., Azooz M.A., Preparation and characterization of some ferromagnetic glass-ceramics contains high quantity of magnetite, Ceram Int., 2009, 35, 1539-1544.

[81] Kawashita M., Iwahashi Y., Kokubo P.T., Yao P.T., Preparation of Glass Ceramics Containing Ferrimagnetic Zinc Iron Ferrite for the Hyperthermal Treatment of Cancer, J. Ceram. Soc. Japan 2004, 379, 373-379.
[82] Kumar R., Kothiyal G.P., Srinivasan A., Magnetic and structural properties of $\mathrm{CaO}$ - SiO2 - P2O5 - Na2O - Fe2O3 glass ceramics, J. Magn. Magn. Mater., 2008, 320, 1352-1356.

[83] Martinelli J.R., Sene F.F., Kamikawachi C.N., Partiti C.S.D.M., Cornejo D.R., Synthesis and characterization of glass - ceramic microspheres for thermotherapy, J. Non-Cryst. Solids, 2010, 356, 2683-2688.

[84] Kawashita M., Tanaka M., Kokubo T., Inoue Y., Preparation of ferrimagnetic magnetite microspheres for in situ hyperthermic treatment of cancer, Biomaterials, 2005, 26, 2231-2238.

[85] Zhang J., Wang D., Huang W., Preparation and Characterization of Fe203-SiO2-Y2O3-Al2O3 Ferromagnetic glass ceramics microspheres for hyperthermia application, J. Chinese Ceram. Soc., 2011, 39, 923-926.

[86] Vanea E., Tamasan M., Albon C., Simon V., Synthesis and characterisation of a new composite aluminosilicate bioceramic, J. Non-Cryst. Solids, 2011, 357, 3791-3796.

[87] Abdel-hameed S., Kady A.E., Effect of different additions on the crystallization behavior and magnetic properties of magnetic glass - ceramic in the system $\mathrm{Fe} 2 \mathrm{O} 3-\mathrm{ZnO}-\mathrm{CaO}-\mathrm{SiO} 2, \mathrm{~J} . \mathrm{Adv}$. Res., 2012, 3, 167-175.

[88] Liu J.A., Yang X.N., Zhang M.M., Preparation and Characterization of Bioactive and Magnetic Biphasic Thermo-Seeds Material, Adv. Mater. Res., 2013, 834-836, 301-304.

[89] Liu J., Zhang M., Yang X., Preparation and Characterization of Coprecipitation-derived Ferromagnetic Glass-ceramic for Hyperthermia Application, Adv. Mater. Res., 2014, 836, 297-300.

[90] Shankhwar N., Kothiyal G.P., Srinivasan A., Understanding the magnetic behavior of heat treated $\mathrm{CaO}$ - P2O5 - Na2O - Fe2O3 - SiO2 bioactive glass using electron paramagnetic resonance studies, Phys. B Phys. Condens. Matter, 2014, 448, 132-135.

[91] Hench L.L., Bioceramics - From Concept To Clinic, J. Am. Ceram. Soc., 1991, 74, 1487-1510.

[92] Abdel-Hameed S.A.M., El-Kady A.M., Marzouk M.A., Magnetic glass ceramics for sustained 5-fluorouracil delivery: Characterization and evaluation of drug release kinetics, Mater. Sci. Eng. C, 2014, 44, 293-309.

[93] Sharma K., Dixit A., Singh S., Jagannath Bhattacharya S., Prajapat C.L., Preparation and studies on surface modifications of calcium-silico-phosphate ferrimagnetic glass-ceramics in simulated body fluid, Mater. Sci. Eng. C, 2009, 29, 2226-2233.

[94] Karkan S.F., Mohammadhosseini M., Panahi Y., Zarghami N., Akbarzadeh A., Abasi E., Magnetic nanoparticles in cancer diagnosis and treatment: a review, Artif. Cells, Nanomed. Biotechnol., 2016, 45, 1-5.

[95] Saqlain A., Shah M.U., Hashmi S., Alam A., Shamim A., Magnetic and bioactivity evaluation of ferrimagnetic $\mathrm{ZnFe} 204$ containing glass ceramics for the hyperthermia treatment of cancer, J. Magn. Magn. Mater., 2010, 322(3), 75-81.

[96] Shah S.A., Hashmi M.U., Alam S., Shamim A., Magnetic and bioactivity evaluation of ferrimagnetic $\mathrm{ZnFe} 2 \mathrm{O} 4$ containing glass ceramics for the hyperthermia treatment of cancer, J. Magn. Magn. Mater., 2010, 322, 375-81.

[97] Saqlain A., Shah M.U., Hashmi S., Alam S., Effect of aligning magnetic field on the magnetic and calorimetric properties of ferrimagnetic bioactive glass ceramics for the hyperthermia treatment of cancer., Mater. Sci. Eng. C, 2011, 31, 1010-1016.

[98] Singh R.K., Srinivasan A., Apatite-forming ability and magnetic properties of glass-ceramics containing zinc ferrite and calcium sodium phosphate phases, Mater. Sci. Eng. C, 2010, 30, 1100- 
1105.

[99] Singh R.K, Srinivasan A., Magnetic properties of bioactive glassceramics containing nanocrystalline zinc ferrite, J. Magn. Magn. Mater., 2011, 323, 330-333.

[100] Singh A., Rajendra K., Apatite-forming ability and magnetic properties of glass-ceramics containing zinc ferrite and calcium sodium phosphate phases, Mater. Sci. Eng. C, 2010, 30, 11001106.

[101] Singh A., Rajendra K., Magnetic properties of bioactive glassceramics containing nanocrystalline zinc ferrite, J. Magn. Magn. Mater., 2011, 323(3), 330-333.

[102] Shah S.A., Hashmi M.U., Shamim A., Alam S., Study of an anisotropic ferrimagnetic bioactive glass ceramic for cancer treatment, Appl. Phys. A Mater. Sci. Proc., 2010, 100, 273-80.

[103] Saqlain A., Shah M.U., Hashmi A., Shamim S., Study of an anisotropic ferrimagnetic bioactive glass ceramic for cancer treatment., Appl. Phys. A, 2010, 100, 273-280.

[104] Shankhwar N., Srinivasan A., Evolution of Magnetic and Bone Mineral Phases in Heat-Treated Bioactive Glass Containing Zinc and Iron Oxides, Int. J. Appl. Glass Sci., 2016, 8, 105-115.

[105] Jiang Y., Ou J., Zhang Z., Qin Q.H., Preparation of magnetic and bioactive calcium zinc iron silicon oxide composite for hyperthermia treatment of bone cancer and repair of bone defects, J. Mater. Sci. Mater. Med., 2011, 22, 721-729.

[106] Intawin P., Leenakul W., Jantaratana P., Pengpat K., Fabrication of SrFe12019-P2O5-CaO-Na2O bioactive glass-ceramics at various sintering temperatures, J. Ferroelectrics, 2015, 489, 35-42.

[107] Leenakul W., Intawin P., Ruangsuriya J., Jantaratana P., Magnetic Bioactive SrFe12019-SiO2-CaO-Na2O-P2O5 Glass-Ceramics for Hyperthermia Treatment of Bone Cancer, Integr. Ferroelectrics, 2013, 148, 37-41.

[108] Leenakul P., Intawin J., Ruangsuriya P., Jantaratana W., Pengpat K., Magnetic Bioactive SrFe12019-SiO2-CaO-NaO5 GlassCeramics for Hyperthermia Treatment of Bone, Integr. Ferroelectrics, 2013, 148, 81-89.

[109] Abbasi M., Hashemi B., Shokrollahi H., Investigating in vitro bioactivity and magnetic properties of the ferrimagnetic bioactive glass-ceramic fabricated using soda-lime-silica waste glass, J. Magn. Magn. Mater., 2014, 356, 5-11.

[110] Abbasi B., Hashemi H., Shokrollahi M., Investigating in vitro bioactivity and magnetic properties of the ferrimagnetic bioactive glass-ceramic fabricated using soda-lime-silica waste glass, J. Magn. Magn. Mater., 2014, 356, 5-11.

[111] Intawin P., Leenakul W., Jantaratana P., Fabrication and Magnetic Properties of P2O5-CaO-Na2O Bioactive Glass Ceramic Containing BaFe12019., Integr. Ferroelectrics, 2013, 148, 171-177.

[112] Leenakul W., Intawin P., Tunkasiri T., Ruangsuriya J., Pengpat K., Preparation of ferrimagnetic BF based silicate glass system, Ceram Int., 2015, 41, S464-S470.

[113] Jagadish B.R., Studies on synthesis of calcium ferrite-based bid glass ceramics, Bulletin Mater. Sci., 1998, 21(2), 133-137.

[114] Da Li G., Zhou D.L., Lin Y., Pan T.H., Chen G.S., Yin Q.D., Synthesis and characterization of magnetic bioactive glass-ceramics containing Mg ferrite for hyperthermia, Mater. Sci. Eng. C, 2010, 30, 148-153.

[115] Guang D.L., Pan T.H., Chen G.S., Lin Y., Mao M., Yan G.,. Effect of $\mathrm{Mn}$-Zn ferrite on apatite-wollastonite glass-ceramic (A-W GC), Biomed. Mater., 2009, 4(4), 045001.

[116] Abe T., Kishi T., Yasumori A., Magnetic properties of glass ceramic wire in Fe304-TiO2-SiO2 system., J. Phys., 2009, 191,
012023.

[117] Hui-Ju Moo-Chin W., Crystallization kinetics and magnetic properties of iron oxide contained 25LiO2-20CaO-2P205-45SiO2 glasses, J. Europ. Ceram. Soc., 2007, 27, 3171-3176.

[118] Vahak M., Nano-Glass Ceramics Processing, Properties and Applications, Nano-Glass Ceramics, 2015, Elsevier.

[119] Marghussian V., Other Applications of Nano-Glass Ceramics. Nano-Glass Ceramics, 2015, Elsevier.

[120] Arcos D., Del Real R.P., Vallet-Regí M., A novel bioactive and magnetic biphasic material, Biomaterials, 2002, 23(10), 21512158.

[121] Arcos D., del Real R.P., Vallet-Regí M., Biphasic materials for bone grafting and hyperthermia treatment of cancer, J. Biomed. Mater. Res., 2003, 65, 71-78.

[122] Shah S.A., Hashmi M.U., Alam S., Effect of aligning magnetic field on the magnetic and calorimetric properties of ferrimagnetic bioactive glass ceramics for the hyperthermia treatment of cancer., Mater. Sci. Eng. C., 2011, 31, 1010-1016.

[123] Ruiz-Hernández E., Serrano M.C., Arcos D.VR., Glass-glass ceramic thermoseeds for hyperthermic treatment of bone tumors, Biomed. Mater. Res., 2006, 33, 97-103.

[124] Hsi C.S., Cheng H.Z., Hsu H.J., Chen Y.S., Wang M.C., Crystallization kinetics and magnetic properties of iron oxide contained 25Li20-8MnO2-20CaO-2P2O5-45SiO2 glasses., J. Europ. Ceram. Soc., 2007, 27, 3171-3176.

[125] Li G., Zhou D., Xue M., Yang W., Long Q., Cao B., Study on the surface bioactivity of novel magnetic A-W glass ceramic in vitro, Appl. Surf. Sci., 2008, 255, 559-561.

[126] Serrano M.C., Portolés M.T., Pagani R., de Guinoa J.S., RuizHernández E., Arcos D., In vitro Positive Biocompatibility Evaluation of Glass-Glass Ceramic Thermoseeds for Hyperthermic Treatment of Bone Tumors, Tissue Eng. Part A, 2008, 14, 617-627.

[127] Kothiyal G.P., Kumar R., Dixit A., Sharma K., Goswami M., Thermophysical and structural studies on some glass-ceramics and role of nano size crystallites, Conf. Ser. Mater. Sci. Eng., 2009, 2, 12005.

[128] Li G., Feng S., Zhou D., Magnetic bioactive glass ceramic in the system CaO-P2O5-SiO2-MgO-CaF2-MnO2-Fe2O3 for hyperthermia treatment of bone tumor, J. Mater. Sci. Mater. Med., 2011, 22, 2197-2206.

[129] Tadić M., Marković D., Spasojević V., Kusigerski V., Remškar M., Pirnat J., Synthesis and magnetic properties of concentrated $\alpha$-Fe203 nanoparticles in a silica matrix, J. Alloys Compd., 2007, 441, 291-296.

[130] Zysler R., Fiorani D., Testa A., Investigation of magnetic properties of interacting Fe2O3 nanoparticles, J. Magn. Magn. Mater., 2001, 224, 5-11.

[131] Abdel-Hameed S.A.M., Marzouk M.A., Elwan R.L., In vitro evaluation of some types of ferrimagnetic glass ceramics, Int. J. Biomater., 2014, 415854.

[132] Verné E., Miola M., Ferraris S., Bianchi C.L., Naldoni A., Maina G., Surface activation of a ferrimagnetic glass-ceramic for antineoplastic drugs grafting, Adv. Eng. Mater., 2010, 12, 309-319.

[133] Bretcanu 0., Ferraris S., Miola M. , Ferrimagnetic glass-ceramics for magnetic induction hyperthermia, Adv. Bioceram. Biotechnol., 2010, 244.

[134] Alcaide M., Ramírez-Santillán C., Feito M.J., De La Concepción Matesanz M., Ruiz-Hernández E., Arcos D., In vitro evaluation of glass-glass ceramic thermoseed-induced hyperthermia on human osteosarcoma cell line, J. Biomed. Mater. Res. Part A, 
2012, 100, 64-71.

[135] Ferraris S., Zhang X., Prenesti E., Corazzari I., Turci F., Tomatis M., Gallic acid grafting to a ferrimagnetic bioactive glass-ceramic, J. Non-Cryst. Solids., 2016, 432, 167-175.

[136] Verné E., Bruno M., Miola M., Maina G., Bianco C., Cochis A., Composite bone cements loaded with a bioactive and ferrimag. netic glass-ceramic: Leaching, bioactivity and cytocompatibility., Mater. Sci Eng C., 2015,53,95-103.

[137] Ohura K., Ikenaga M., Nakamura T., Yamamuro T., A HeatGenerating Bioactive Glass-Ceramic for Hyperthermia, J. Appl. Biomater., 1991, 2, 153-159.

[138] Kokubo T., Kotoura Y., Oka M., Bioactivity of CaO . S i 02 glasses added with various ions, J. Mater. Sci.: Mater. Med., 1992, 3, $95-$ 100.

[139] Vallet-Regí M., Arcos D., Pérez-Pariente J., Evolution of porosity during in vitro hydroxycarbonate apatite growth in sol-gel glasses, J. Biomed. Mater. Res., 2000, 51, 23-28.

[140] Goel A., Shaaban E.R., Oliveira J.B., Sá M.A., Pascual M.J., Ferreira J.M.F., Sintering behavior and devitri fi cation kinetics of iron containing clinopyroxene based magnetic glass-ceramics, Solid State Ionics, 2011, 186, 59-68.

[141] Singh K., Bahadur D., Characterization of SiO2-Na2O-Fe2O3CaO-P205-B2O3 glass ceramics, J. Mater. Sci.: Mater. Med., 1999, 10(8), 481-484.

[142] Hiroki N., Tetsuo K., Yuji M., Ryuji Tamura K.T., Magnetic and Electric Properties of Phase Separated Glass Ceramics in CoOTiO2-SiO2 System, Mater. Res., 2009, 1118, $15-7$.

[143] Kokubo T., Bioactive glass ceramics: properties and applications., Biomaterials, 1991, 12, 155-163.

[144] Takegami K., Sano T., Wakabayashi H., Sonoda J., Yamazaki T., Morita S., New Ferromagnetic Bone Cement for Local Hyperthermia., J. Biomed. Mater. Res., 1997, 43, 210-214.

[145] Bruno M., Miola M., Bretcanu O., Vitale-brovarone C., Gerbaldo R., Laviano F., Composite bone cements loaded with a bioactive and ferrimagnetic glass-ceramic Part I: Morphological, mechanical and calorimetric characterization, J. Biomater. Appl., 2014, 29, 254-267.

[146] Konaka H., Miyaji F., Kokubo T., Preparation and magnetic properties of glass-ceramics containing $\alpha$-Fe for hyperthermia., J. Ceram. Soc. Japan, 1997, 105, 833-836.

[147] Ei-Kheshen A., Ei-Bassyouni G., Abdel-Kader A., Effect of composition on bioactivity and magnetic properties of glass / ceramic composites for hyperthermia, Interceram., 2011, 60, 379-382.

[148] Leenakul W., Kantha P., Pisitpipathsin N., Rujijanagul G., Eitssayeam S., Pengpat K., Structural and magnetic properties of SiO2-CaO-Na2O-P2O5 containing $\mathrm{BaO}-\mathrm{Fe} 2 \mathrm{O} 3$ glass-ceramics, J. Magn. Magn. Mater., 2013, 325, 102-106.
[149] Wilaiwan L., Jetsada R., Pongsakorn J.K.P., Fabrication and characterization of ferromagnetic bioactive glass-ceramic containing BaFe12019, Ceram. Int., 2013, 39, 201-205.

[150] Liu J., Zhang M., Yang X., A Novel Porous Ferromagnetic Glassceramic for Hyperthermia Application., Appl. Mech. Mater., 2014, 454, 288-291.

[151] Kokubo T., Kushitani H., Sakka S., Kitsugi T., Yamamum T., Solutions able to reproduce in vivo Surface-Structure Changes in Bioactive, J. Biomed. Mater. Res., 1990, 24, 721-734.

[152] Filho O.P., La Torre G.P., Hench L.L., Effect of crystallization on apatite-layer formation of bioactive glass 45S5, 1996, 30(4), 509514.

[153] Singh A., Srinivasan A., Bioactivity of SiO2-CaO-PO glasses containing zinc-iron oxide, Appl. Surf. Sci., 2010, 256, 1725-1730.

[154] Gamal-eldeen A.M., Abdel-hameed S.A.M., El-daly S.M., Abozeid M.A.M., Swellam M.M., Cytotoxic effect of ferrimagnetic glass-ceramic nanocomposites on bone osteosarcoma cells, Biomed. Pharmacother., 2017, 88, 689-697.

[155] Wang Y.Y., Li B., Luo W.Q., Cao F., Bioactivity of Fe2O3-CaO-SiO2 glass ceramics modified through the addition of $\mathrm{P} 205$ and TiO2, Ceram. Int., 2017, 43, 6738-6745.

[156] Bretcanu O., Miola M., Bianchi C.L., Marangi I., Carbone R., Corazzari I., In vitro biocompatibility of a ferrimagnetic glassceramic for hyperthermia application, Mater. Sci. Eng. C, 2016, 12, 105.

[157] Miola M., Laviano F., Bruno M., Lombardi A., Cochis A., Rimondini L., Composite bone cements for hyperthermia: modeling and characterization of magnetic, calorimetric and in vitro heating properties., Ceram. Int., 2016, 12, 049.

[158] Matsumoto M., Yoshimura N., Honda Y., Hiraoka M., Ohura K., Ferromagnetic hyperthermia in rabbit eyes using a new glassceramic thermoseed, Graefe's Arch Clin. Exp. Ophthalmol., 1994, 176-181.

[159] Rao C.N.R., Mahesh R., Raychaudhuri A.K., Mahendiran R., Giant magnetoresistance, charge ordering and other novel properties of perovskite manganates, J. Phys. Chem. Solids., 1998, 59, 487502.

[160] Kuznetsov A.A., Shlyakhtin O.A., Brusentsov N.A., Kuznetsov O.A., "Smart" mediators for self-controlled inductive heating, Europ. Cells Mater., 2002, 3, 75-77.

[161] Wilson J., Pigott G.H., Toxicology and biocompatibility of bioglasses, J. Biomed. Mater. Res., 1981, 15, 805-817. 